\title{
Characterization of a Pressure-Fed Liquid Oxygen/Liquid Methane Reaction Control System Under Simulated Altitude and Thermal Vacuum Conditions
}

\author{
Matthew J. Atwell ${ }^{1}$, John C. Melcher ${ }^{2}$, Eric A. Hurlbert ${ }^{3}$, and Robert L. Morehead ${ }^{4}$ \\ NASA Johnson Space Center, Houston, TX, 77058, United States
}

\begin{abstract}
A liquid oxygen (LOX)/liquid methane (LCH4) Reaction Control System (RCS) was tested at NASA Glenn Research Center's Plum Brook Station in the Spacecraft Propulsion Research Facility (B-2) under simulated altitude and thermal vacuum conditions. The RCS is a subsystem of the Integrated Cryogenic Propulsion Test Article (ICPTA) and was initially developed under Project Morpheus. Composed of two 28 lbf-thrust and two 7 lbf-thrust engines, the RCS is fed in parallel with the ICPTA main engine from four propellant tanks. Forty tests consisting of 1,010 individual thruster pulses were performed across 6 different test days. Major test objectives were focused on system dynamics, and included characterization of fluid transients, manifold priming, manifold thermal conditioning, Thermodynamic Vent System (TVS) performance, and main engine/RCS interaction. Peak surge pressures from valve opening and closing events were examined. It was determined that these events were impacted significantly by vapor cavity formation and collapse. In most cases, the valve opening transient was more severe than the valve closing. Under thermal vacuum conditions it was shown that TVS operation is unnecessary to maintain liquid conditions at the thruster inlets. However, under higher heat leak environments, the RCS can still be operated in a self-conditioning mode without overboard TVS venting, contingent upon a sufficient duty cycle and the engines managing a range of potentially severe thermal transients. Lastly, the engines experienced significant ignition problems during testing under cold thermal conditions. Successful ignition was demonstrated only after warming the thruster bodies with a gaseous nitrogen purge to an intermediate temperature.
\end{abstract}

\section{Nomenclature}

$A P S T B=$ Auxiliary Propulsion System Test Bed

atm $=$ atmosphere

$B T U=$ British Thermal Unit

COP $\quad=$ Coil-on-plug

$\mathrm{Hz} \quad=$ Hertz

ICPTA = Integrated Cryogenic Propulsion Test Article

$J S C=$ Johnson Space Center

$\mathrm{LCH} 4=$ Liquid Methane

$L O X=$ Liquid Oxygen

$M I B=$ Minimum Impulse Bit

\footnotetext{
${ }^{1}$ Propulsion System Engineer, Propulsion Systems Branch EP4, AIAA Member

${ }^{2}$ Propulsion System Engineer, Propulsion Systems Branch EP4, AIAA Member Senior Member

${ }^{3}$ Propulsion System Engineer, Propulsion Systems Branch EP4, AIAA Member

${ }^{4}$ Propulsion System Engineer, Propulsion Systems Branch EP4, AIAA Member
} 


$\begin{array}{ll}M L I & =\text { Multi-Layer Insulation } \\ M R & =\text { Mixture Ratio } \\ m J & =\text { megajoule } \\ m s & =\text { millisecond } \\ P C A D & =\text { Propulsion and Cryogenics Advanced Development } \\ \text { psi } & =\text { pounds per square inch } \\ \text { psia } & =\text { pounds per square inch absolute } \\ \text { psid } & =\text { pounds per square inch differential } \\ R C S & =\text { Reaction Control System } \\ T V S & =\text { Thermodynamic Vent System }\end{array}$

\section{Introduction}

$\mathrm{T}$ HE development of liquid oxygen (LOX)/liquid methane (LCH4) propulsion system technology became a priority for NASA over the last decade after the propellant combination was identified as an ideal candidate for exploration architectures during the Constellation Program. ${ }^{1}$ Advantages over other potential candidate propellants include low toxicity, high performance, space storability, commonality with other spacecraft subsystem fluids (i.e. fuel cells, life support), and in-situ resource utilization compatibility. ${ }^{2}$ Many of the technology risks identified with the propellant combination pertain to Reaction Control System (RCS) applications. To date, no cryogenic RCS has flown in space, and integrated system-level testing in a thermal vacuum environment has not been performed. A significant amount of work was performed during the Propulsion and Cryogenics Advanced Development (PCAD) program to address some of the gaps in LOX/LCH4 reaction control engine development, including ignition reliability and performance. ${ }^{1}$ Other work focused on how to effectively manage and distribute properly conditioned propellants. Integrated RCS testing was performed using some of the resulting Aerojet-developed engines at NASA White Sands Test Facility on the Auxiliary Propulsion System Test Bed (APSTB) with positive results. ${ }^{3}$ Because the APSTB was designed for Space Shuttle system development however, it was significantly oversized for this application. A follow-on effort to develop an article more appropriately sized for testing was conceived of in the Integrated Propulsion Systems Test Bed. ${ }^{4}$ This effort was intended to focus more on integrated system operating characteristics and serve as an anchor to validate fluid and thermal models; however it was cancelled after CDR when the PCAD project ended with the Constellation Program.

In addition to the work under PCAD, significant LOX/LCH4 RCS development work was completed during Project Morpheus, starting in 2010. The Morpheus vehicle utilized a pressure-fed LOX/LCH4 propulsion system composed of a single 5,000 lbf-thrust main engine and four reaction control engines. As a part of the project, a 20 lbf-thrust LOX/LCH4 engine capable of operating across a wide range of inlet temperatures and pressures was developed for the RCS. ${ }^{5}$ A large set of development tests were performed on these engines to characterize performance. These tests were followed by a flight campaign in which the whole RCS was tested in an atmospheric environment over a wide range of operating modes.

Some of the vehicle subsystem hardware was removed after completion of the Morpheus flight campaign, and what remained was leveraged to create the Integrated Cryogenic Propulsion Test Article (ICPTA) using the Morpheus propulsion system as a framework. The first ICPTA test campaign was completed in 2015 after upgrading to an active pressurization system with cold helium storage and replacing the Morpheus main engine with a 2,000 lbf-thrust engine. ${ }^{6}$

The present effort to be discussed is focused on a test campaign at NASA Glenn Research Center's Plum Brook Station in the Spacecraft Propulsion Research Facility (B-2). A detailed overview of the test campaign and its objectives are discussed in Ref. 7. The primary test goal for the RCS was characterization of feed system fluid and thermal transients. Data obtained will be used to anchor thermal and fluid models. Important test objectives included: manifold priming dynamics, manifold thermal conditioning in various heat leak environments, fluid transient characterization (water hammer), main engine/RCS interaction, thermodynamic vent system characterization, engine operating characteristics under thermal vacuum conditions, and system-level coil-on-plug (COP) demonstration.

\section{Reaction Control System Design and Test Overview}

In its current configuration, the ICPTA is composed of a single 2,800 lbf-thrust main engine, two 28 lbf-thrust RCS engines, and two $7 \mathrm{lbf}$-thrust RCS engines (Figure 1). Propellants are stored in four 48-inch diameter 5083 aluminum tanks that feed the main engine and RCS engines in parallel. The propellant tanks and lines are insulated by a $6 \mathrm{~mm}$ layer of Pyrogel XT surrounded by nine layers of multi-layer insulation (MLI). Each MLI layer consists 
of a 1 mil polyester film (PET) radiation barrier separated by two layers of polyester B4A netting. Helium is stored cryogenically in a composite overwrapped pressure vessel and flows through a heat exchanger on the main engine before being used to pressurize the propellant tanks to a design operating pressure of 325 psia. Figure 2 shows a simplified diagram of the ICPTA propulsion fluid system. For some RCS-only tests the system is operated in blowdown since the main engine heat exchanger is not functional without the main engine running. The ICPTA is capable of simultaneous main engine and RCS operation.

The RCS engines utilize a COP ignition system designed for operation in a vacuum environment, thus eliminating corona discharge issues associated with a high-voltage lead. ${ }^{8}$ Two RCS pods are located on the ICPTA, with two

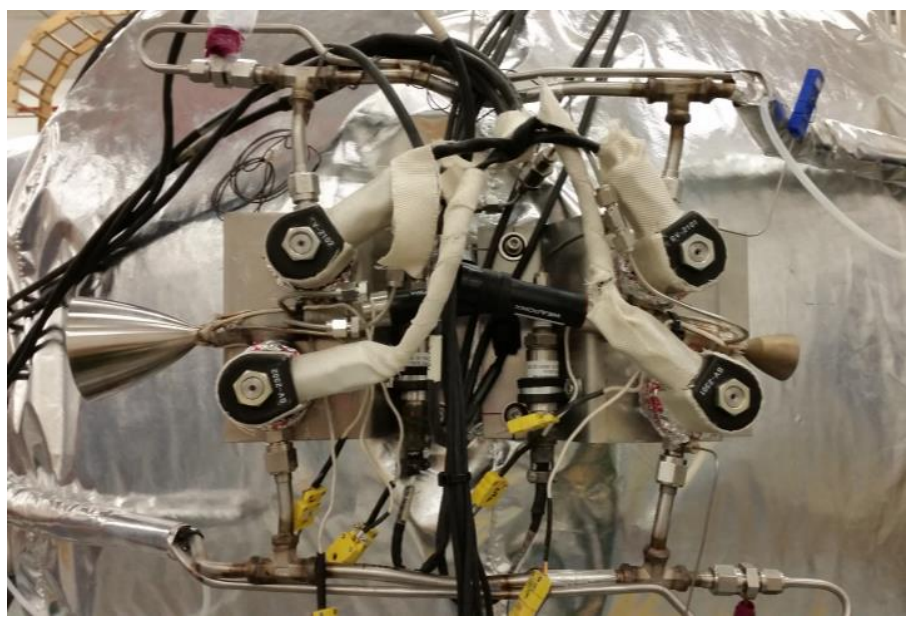

Figure 1. RCS pod with 7 lbf-thrust and 28 lbf-thrust engines, shown uninsulated.

engines on each pod. One of these two engines is a heritage flight engine from Project Morpheus. Its sea-level nozzle has been removed and replaced by an 85:1 nozzle machined using Inconel 718, resulting in a maximum thrust of $28 \mathrm{lbf}$ under vacuum conditions. The other engine is a scaled-down version of the $28 \mathrm{lbf}$-thrust engine, which was designed to match the core and overall mixture ratios (MRs), as well as other injector characteristics. This second engine can produce a maximum thrust of $7 \mathrm{lbf}$ with an 85:1 nozzle that was additively manufactured using Inconel 718. This engine was included in the test series since it represents a more applicable thrust level for a spacecraft of this size. ${ }^{2}$ Both engines are film-cooled and capable of limited duration gas-gas and gas-liquid operation, as well as steady-state liquid-liquid operation.

Each pod contains one of each variant, such that two engines of the same thrust level can be fired as a couple on opposite pods. The RCS feed system is composed of symmetrical propellant lines that tap off of the main propellant manifold to send LOX and LCH4 outboard to the two RCS pods. A Thermodynamic Vent System (TVS) is used to condition propellants at each pod by venting through an orifice and then routing the cold expansion products back through tubing that is welded along a large portion of the main RCS feed lines.

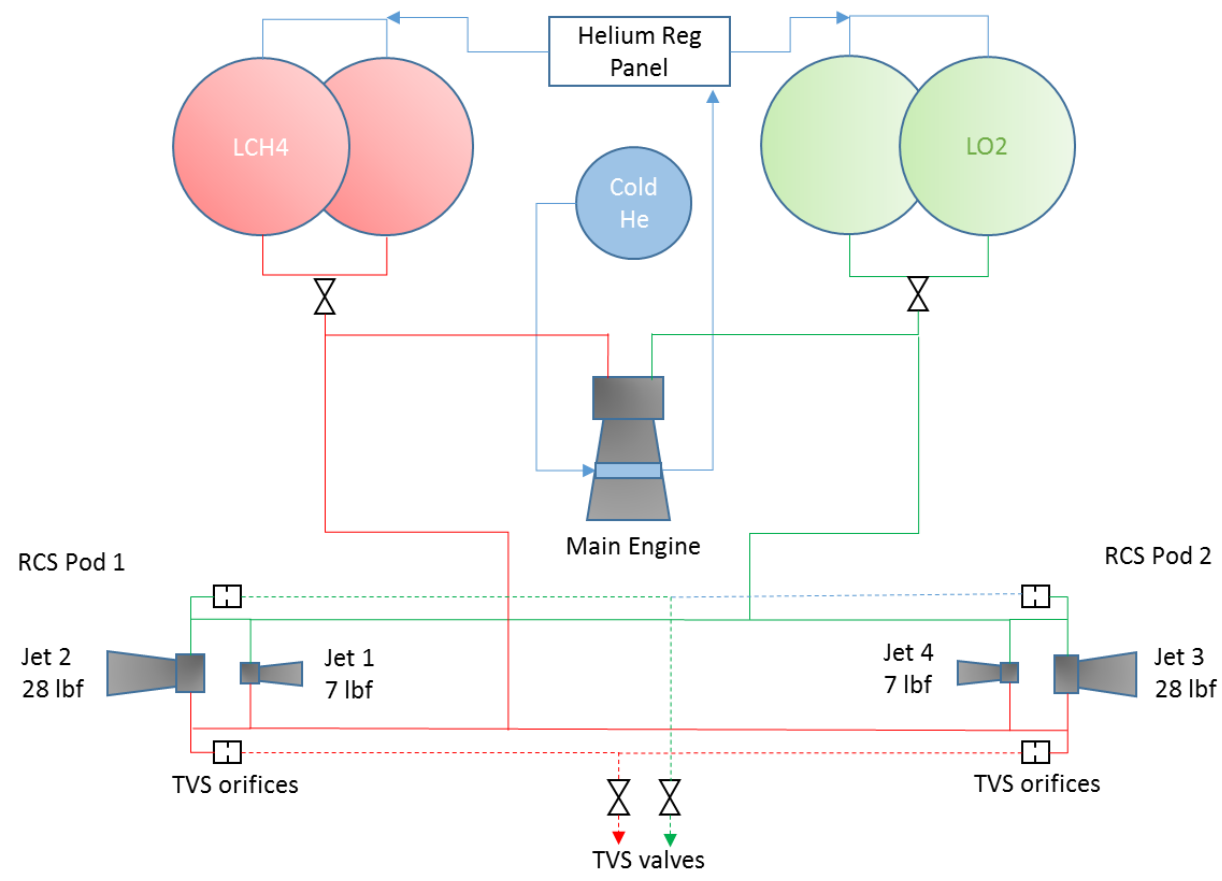

Figure 2. Simplified fluid schematic of the ICPTA including RCS with TVS. 


\section{A. Instrumentation}

The ICPTA was instrumented with more than 320 sensors to collect temperature, pressure, flow rate, force and strain data. Of those sensors, 42 directly measured RCS quantities. The measurements were collected across three data acquisition systems. First, all critical instrumentation that needed to be monitored during a test were tied into the ICPTA Avionics and Power Unit. These channels are monitored at $100 \mathrm{~Hz}$ and can be viewed real-time in the control room during a test. Less critical instrumentation that did not require real-time monitoring (i.e. load cells, certain manifold thermocouples) were recorded on a separate data acquisition system provided by the Plum Brook facility. These channels were also recorded at $100 \mathrm{~Hz}$ during a test. Finally, a set of sensors were recorded on a Dewetron high-speed data acquisition system provided by the Plum Brook facility at 25,000 Hz. These sensors included dynamic pressure transducers on the main engine and in the RCS manifolds.

RCS instrumentation included pressure and temperature sensors at multiple points throughout the system. An Omega PX-309 static pressure transducer was used to monitor engine chamber pressure on each of the four engines. Health was also monitored using three welded-on type $\mathrm{K}$ thermocouples at the throat of each engine. One submerged exposed-tip thermocouple is located on each of the RCS pods (per commodity), thereby allowing for accurate inlet temperature measurements during pulsing transients. In addition, 16 stick-on type $\mathrm{T}$ thermocouples distributed through lines provide insight into the temperature distribution throughout the manifold. Lastly, six cryogenic dynamic-pressure transducers are located in the manifolds to measure fluid transients. There are four total Kulite CTL-190-1000A transducers, and two Kulite CTL-190-100BarA transducers. These sensor outputs were passed through a PFI 28144 signal conditioning card and then directly into the Dewetron data acquisition system.

\section{B. Test Description}

Development and check-out testing was performed at Johnson Space Center (JSC) prior to testing of the ICPTA at Plum Brook in order to reduce technical risk in the thermal vacuum environment. Initial component-level testing was focused on developing confidence in the COP ignition system. A set of thruster-only tests were performed under both ambient and vacuum conditions to verify reliability. System-level testing for the RCS installed on the ICPTA was then performed under ambient sea-level conditions at JSC to verify functionality prior to integration with the Plum Brook facility. More detail on these tests can be found in Ref. 8 .

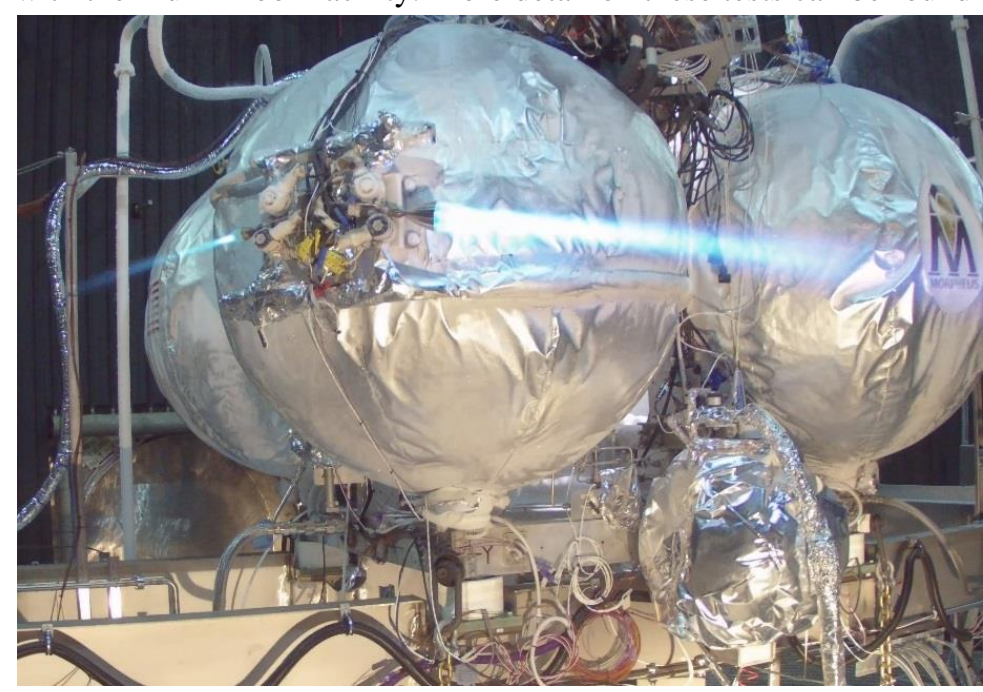

Figure 3. Hotfire testing of both 7 lbf-thrust and 28 lbf-thrust RCS engines under simulated altitude conditions.
The Plum Brook B-2 facility is capable of producing a range of test environments from simulated altitude under ambient thermal conditions to thermal vacuum when the liquid nitrogen cold wall is active in the test cell. The first set of RCS tests were performed at simulated altitude conditions (15-40 torr) with the cold wall inactive. Under these conditions the RCS engines could run for an unlimited duration without significantly affecting the pressure environment of the test cell. These tests included a wide spectrum of engine operating regimes. Low duty cycle sequences consisting of minimum impulse bit (MIB) pulsing were performed, analogous to a coast phase in which the RCS is primarily used for station keeping. Higher duty cycle pulsing tests, analogous to an ascent or landing mission phase, were also performed to stress the system and investigate faster thermal transients. Lastly, some steady-state tests were performed to evaluate thermal soakback and system response times. Figure 3 shows two of the RCS engines operating in the test cell under simulated altitude conditions. The simulated altitude segment of the campaign was composed of 34 test sequences with 987 individual engine pulses.

The second set of RCS tests were performed under a thermal vacuum environment in which the test cell cold wall was approximately $-320^{\circ} \mathrm{F}$ and the pressure was approximately 6 torr. The test article is set up such that the RCS engines had a clear view of the cold wall, and reached steady body temperatures of approximately $-225{ }^{\circ} \mathrm{F}$ prior to testing. Once the manifolds were conditioned from TVS operation, thruster body temperatures approached $320^{\circ} \mathrm{F}$ for some tests. All of these tests consisted of short duration (i.e. MIB or slightly longer) pulses on single or

4

American Institute of Aeronautics and Astronautics 
paired thrusters. This segment of testing was composed of six test sequences with 23 individual engine pulses. A limited set of tests were performed under these conditions due to a combination of test article, commodity, and facility issues.

\section{Results: Fluid Transients}

One of the major objectives for RCS testing was to capture fluid transients under different operating scenarios. The resulting data can then be used to anchor predictive models. To do this, six dynamic pressure transducers were positioned throughout the system to capture pressure peaks and troughs during priming and thruster firing. One of these sensors (Kulite model CTL-190-1000A) was located at the end of each pod per commodity to capture dynamics near the thrusters. The location of these sensors is shown notionally in Figure 4. Two more sensors (Kulite model CTL-190-100BarA) are located where the two RCS manifolds split off from the main propellant feedlines. Because the RCS manifolds are all-welded and have very few existing fittings, limited locations were available to install the sensors; as a result, the transducers are not close-coupled to the thruster inlets, but rather stood off a few inches downstream. For some tests, this configuration served to amplify the pressure waves that resulted from both valve openings and closures. This phenomenon is discussed further below.

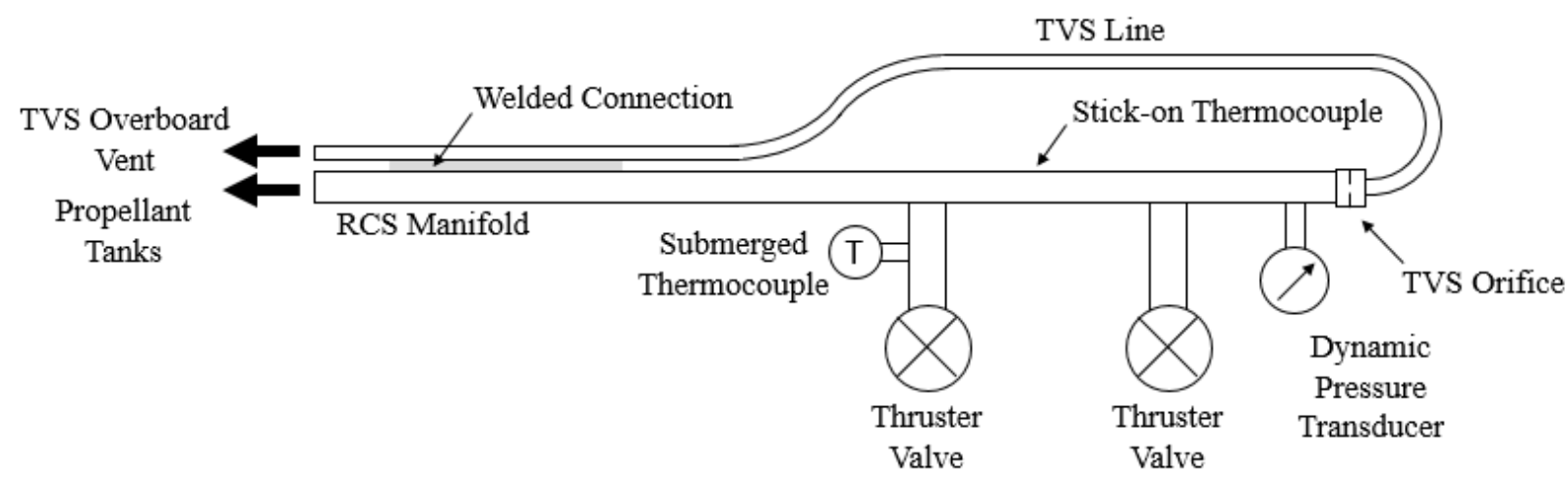

Figure 4. Dynamic pressure sensor pod location and thermocouple location.

\section{A. System Priming}

A set of priming tests were performed to simulate how a spacecraft RCS would be activated before starting nominal operation. During a typical mission scenario, the RCS manifolds would be isolated from the propellant tanks to provide an inhibit against any nominal and off-nominal leakage. The downstream lines would be either vacuum pumped or filled with a low-pressure inert pad gas such as nitrogen. During priming, the isolation valve is opened with some higher pressure upstream, and the propellant subsequently fills the manifold. For a cryogenic propellant, the resulting transient fluid event is a highly complex phenomena in which a multi-phase front advances down the manifold until it reaches the thrust inlets and any other dead-ended sections. ${ }^{9}$ This process produces a water hammer effect and the resulting surge pressure is challenging to predict.

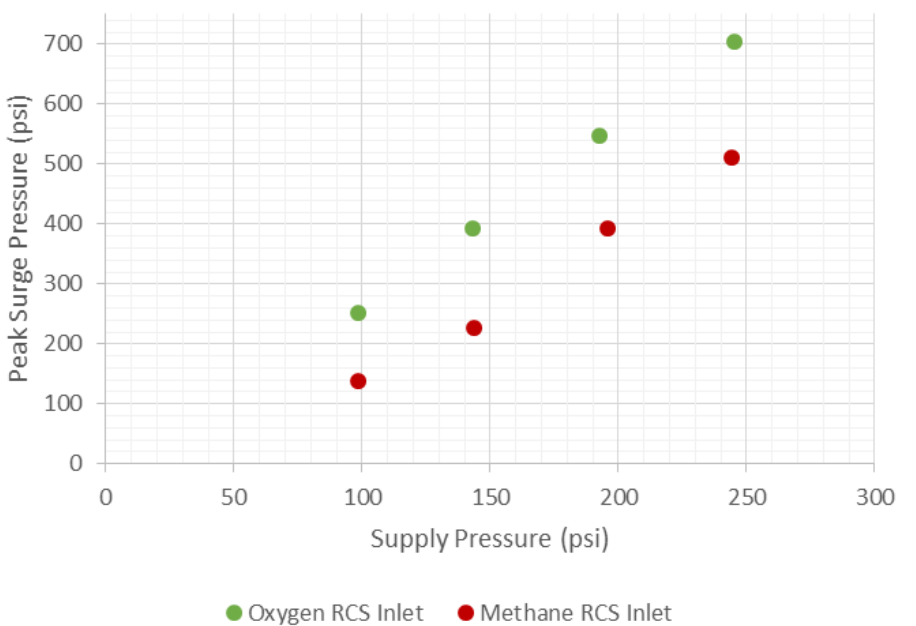

Figure 5. Measured data for priming initial surge pressure at RCS thruster inlet as a function of propellant tank supply pressure. 
Each priming test was performed under simulated altitude and ambient thermal conditions. For all tests, the manifold was filled with nitrogen at a pressure of $1 \mathrm{~atm}$. The propellant tanks were isolated from the manifolds by a 1 inch ball valve and pressurized to various initial starting conditions. The ball valve takes approximately 1 second to actuate from the fully closed to fully opened position. For each test, the manifold reached a steady pressure prior to the valve reaching its fully open position. The rise time to the initial pressure peak at the thruster pods was roughly constant for all tests at 0.3 seconds.

Peak surge pressure at the thruster pod sensor locations is shown in Figure 5 for the eight different tests performed. Both pods for the same propellant commodity measured approximately the same peak, so the average between the two is shown. For the oxygen manifold, the initial peak pressure ranges from 2.6 times the supply pressure on the low end (100 psi test case) to 2.9 times the supply pressure on the high end ( 250 psi test case). For the methane manifold, these amplification values range from 1.4 at the low end to 2.1 at the high end. Skin thermocouples measuring manifold temperature in multiple locations showed little change during these events, thus indicating that liquid propellant never traveled very far down the manifold during any of these tests. As a result, all of these events were characterized by mostly single-phase gas dampening at the thrusters. No priming tests were performed in the cold-thermal environment during this campaign, so future testing will be required to examine the impact that cold manifold hardware has on this process.

\section{B. Water Hammer During Thruster Pulsing}

Valve closing pressure peaks (and sometimes valve opening pressure troughs) can represent a challenge for RCS design and operation. To limit peak pressures, system constraints are sometimes placed on line diameter for a given thruster design. Additional operational constraints can also be required to limit the number of simultaneous valve closures that can occur in one area of the system if the resulting peaks would otherwise exceed maximum design pressure. For some traditional RCS propellants that operate well above their vapor pressure, it is relatively simple to bound the maximum peak pressures that can be encountered from a single valve closure. One approach is to assume an instantaneous valve closure, and for a compressible fluid the resulting pressure rise is given by Eq. (1) where $\rho$ is the fluid density, $a$ is the speed of sound in the fluid, and $\Delta V$ is the flow velocity. ${ }^{10}$

$$
\Delta P=\rho a \Delta V
$$

This methodology can be modified to account for pipe compressibility and other effects.

In the case of a cryogenic propellant, pressure transients can sometimes bring the fluid below its vapor pressure, at which point cavitation will occur. When the resulting vapor cavity collapses, either at a dead-end in the system or at a pocket between liquid volumes, a large local pressure rise can result, which then propagates through the system. This phenomenon has been termed column separation, ${ }^{10}$ and is challenging to bound analytically due to the number

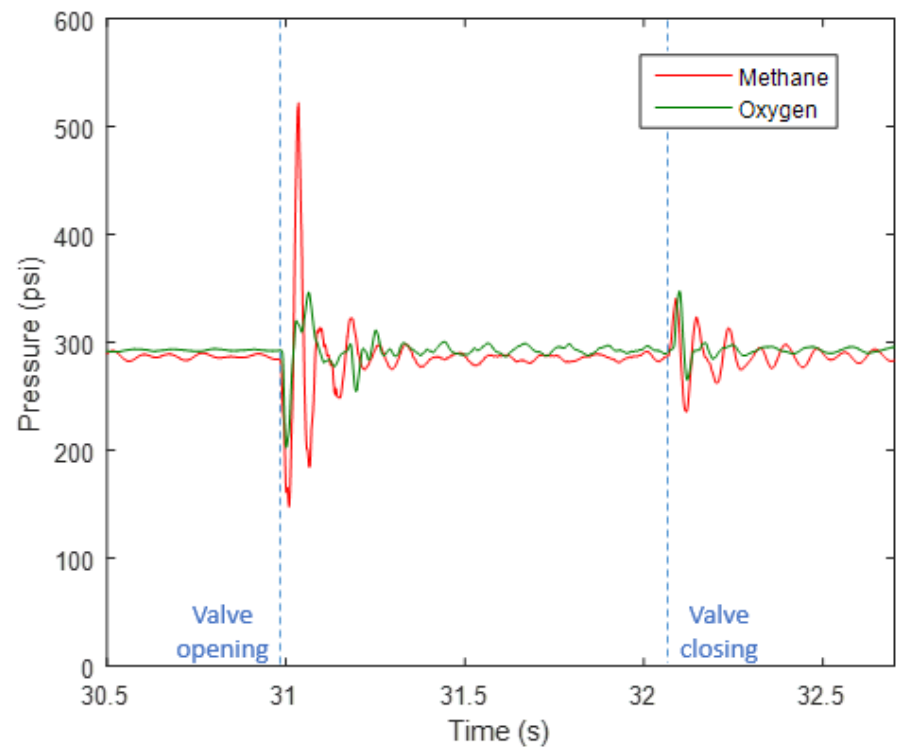

Figure 6. Typical 1 second pulse profile for 28 lbf-thrust engine. of parameters affecting the formation and collapse of these cavities. In addition to cavitation caused by pressure transients, heat transfer from surroundings can also lead to vapor cavity formation inside propellant manifolds, which will then produce similar events during thruster transients. The data indicate that column separation events were common during testing, and potentially attributable to both of these causes.

\section{i. Valve Closing}

A number of tests were performed in which steady engine operation was reached before valve closure. These tests allow for characterization of valve closing peak pressures for each propellant. A typical pressure response profile is shown in Figure 6 for a 1-second single thruster pulse. The pressure peak due to valve closure is shown at approximately 32.1 seconds. In these cases, a 
constant liquid flow rate is established through the valve at the time of closure, resulting in a mild pressure surge. A 5 -second test was performed on each engine during altitude testing under ambient-thermal conditions. These tests represented the most stable mass flow rate prior to shutdown since each engine had adequate time to chill in. The shutdown peak pressures are shown in Table 1 for these four tests. Each of these pulses occurred at an oxygen pressure of 293 psia and a methane pressure of 286 psia. The values are all bounded (within measurement error) by the prediction described above for compressible fluids with instantaneous valve closure, Eq. (1), also shown in Table 1.

Table 1. Pressure peaks for each engine for shutdown after 5 second steady-state operation (propellant tanks at 293 psia LOX and 286 psia LCH4).

\begin{tabular}{|l|c|c|c|c|c|c|}
\hline & Jet $1(7 \mathrm{lbf})$ & Jet $2(28 \mathrm{lbf})$ & Jet $3(28 \mathrm{lbf})$ & Jet $4(7 \mathrm{lbf})$ & $\begin{array}{c}28 \mathrm{lbf} \\
\text { prediction }\end{array}$ & $\begin{array}{c}7 \mathrm{lbf} \\
\text { prediction }\end{array}$ \\
\hline Oxygen & $18 \mathrm{psid}$ & $79 \mathrm{psid}$ & $91 \mathrm{psid}$ & $23 \mathrm{psid}$ & $72 \mathrm{psid}$ & $20 \mathrm{psid}$ \\
\hline Methane & $33 \mathrm{psid}$ & $115 \mathrm{psid}$ & $97 \mathrm{psid}$ & $24 \mathrm{psid}$ & $140 \mathrm{psid}$ & $35 \mathrm{psid}$ \\
\hline
\end{tabular}

A larger spread of shutdown peak pressures is observed for shorter pulses. The results are dependent on the temperature distribution within the manifold and any amplification due to interaction with pressures waves from the startup transient. In general, when the engines were operated with gaseous propellants any closing peaks observed would be of low amplitude and usually within the noise from the startup transient. When saturated propellant conditions existed at the inlets prior to a pulse, a wide spread of pressure peak amplitudes resulted after valve closure, although typically these pulses were short and never reached steady state. For the oxygen manifold during operation of the $7 \mathrm{lbf}$-thrust engine, the spread of pressure peak amplitudes ranged from 5 psid to 30 psid. For the methane manifold on the same engine, they ranged from 20 psid to 63 psid.

Propellant manifolds reached much colder temperatures during thermal vacuum testing than during simulated altitude testing, such that both propellants were subcooled by at least $45^{\circ} \mathrm{F}$. The valve closing peaks that could be identified were of higher magnitude than for the simulated altitude conditions. The oxygen valve closure peak amplitudes ranged from 25 psid to 46 psid for the $7 \mathrm{lbf}$-thrust engine and from 153 psid to 184 psid for the $28 \mathrm{lbf}-$ thrust engines, which are much higher than the values reported in Table 1.

\section{ii. Valve Opening}

The valve opening transients observed during testing often resulted in considerably higher pressures than the static system pressure. These events were typically more pronounced than the valve closing transients and their characteristics are impacted by a wider range of physical phenomena. In the example pulse shown above (Figure 5) the valve opening event occurs at approximately 31 seconds. It can be seen that in the methane manifold the initial pressure trough is proceeded by a large follow-on peak with a magnitude of 522 psia ( $236 \mathrm{psid})$. In the oxygen manifold, the follow-on peak is less pronounced and appears to be damped by a secondary wave interaction. Both of these profiles were seen with both propellants during simulated altitude testing. Follow-on peaks varied greatly in amplitude, from no higher than the closing peak value to upwards of 400 psid (above static pressure). In most cases the amplitude of the peak matches closely with the trough, although there were some test cases in which the followon peak was much smaller than the trough (by a factor of two), and other cases in which it was larger.

A common characteristic for nearly every simulated altitude test case was the condition of the propellants just upstream of the thruster valves. The propellant in the short run connecting the thruster valve to the main manifold run was typically either gaseous or saturated, even when the system was chilled in using the TVS to bring subcooled propellant near the thrusters prior to a test. This condition was measured by a submerged thermocouple located in this section for each thruster pod and is a result of heat leak from the thruster pod and thruster body, which are both at approximately ambient temperature. As a result, during the valve opening transient a small section of gaseous or two-phase propellant flows through the valve prior to liquid propellant reaching the inlet. This section of propellant will evacuate out through the valve faster than the liquid behind it can reach the valve inlet since the liquid has much greater inertia. The result is the large amplitude pressure trough seen in the data. Once the liquid propellant reaches the valve inlet, it is flowing at a higher velocity than under steady engine operating conditions due to this higher pressure differential. The follow-on pressure peak is a result of this higher initial fluid momentum halting when it reaches the valve.

Another impact of vapor cavity formation was observed in the oxygen manifold during a test case that was run with the propellants slightly subcooled. The sequence consisted of a long set of 80-ms pulses spaced 1 second apart. Two pulses were performed on one pod followed by two pulses on the opposite pod, and this was repeated. Figure 7 
shows the dynamic pressure transducer on pod 2 along with the saturation pressure at approximately the same location (calculated using a submerged thermocouple measurement directly upstream). Of the eight pressure troughs shown in the plot, the first, second, fifth, and sixth are due to engine operation on the same pod as the sensor. These four troughs have high magnitudes that are consistent with the phenomenon discussed above. The other four troughs result from thruster operation on the opposite pod and thus have lower magnitudes. For two of these troughs (number 3 and 7), measured fluid pressures stay above the vapor pressure, and the waves damp out quickly after the follow-on peak. For the other two (number 4 and 8), the measured fluid pressure drops below the vapor pressure, and a large secondary peak occurs after the follow-on peak. It is postulated that this could be evidence of column separation occurring at the dead-ended sensor location. Of the 40 waves that come from the opposite pod during this test, 12 fluid pressure troughs drop below the local vapor pressure, and 10 of these exhibit this large secondary peak phenomenon. In contrast, of the 28 fluid pressure waves that do not drop below vapor pressure, only four do not exhibit the normal damping, and for none of these is the follow-on peak larger.

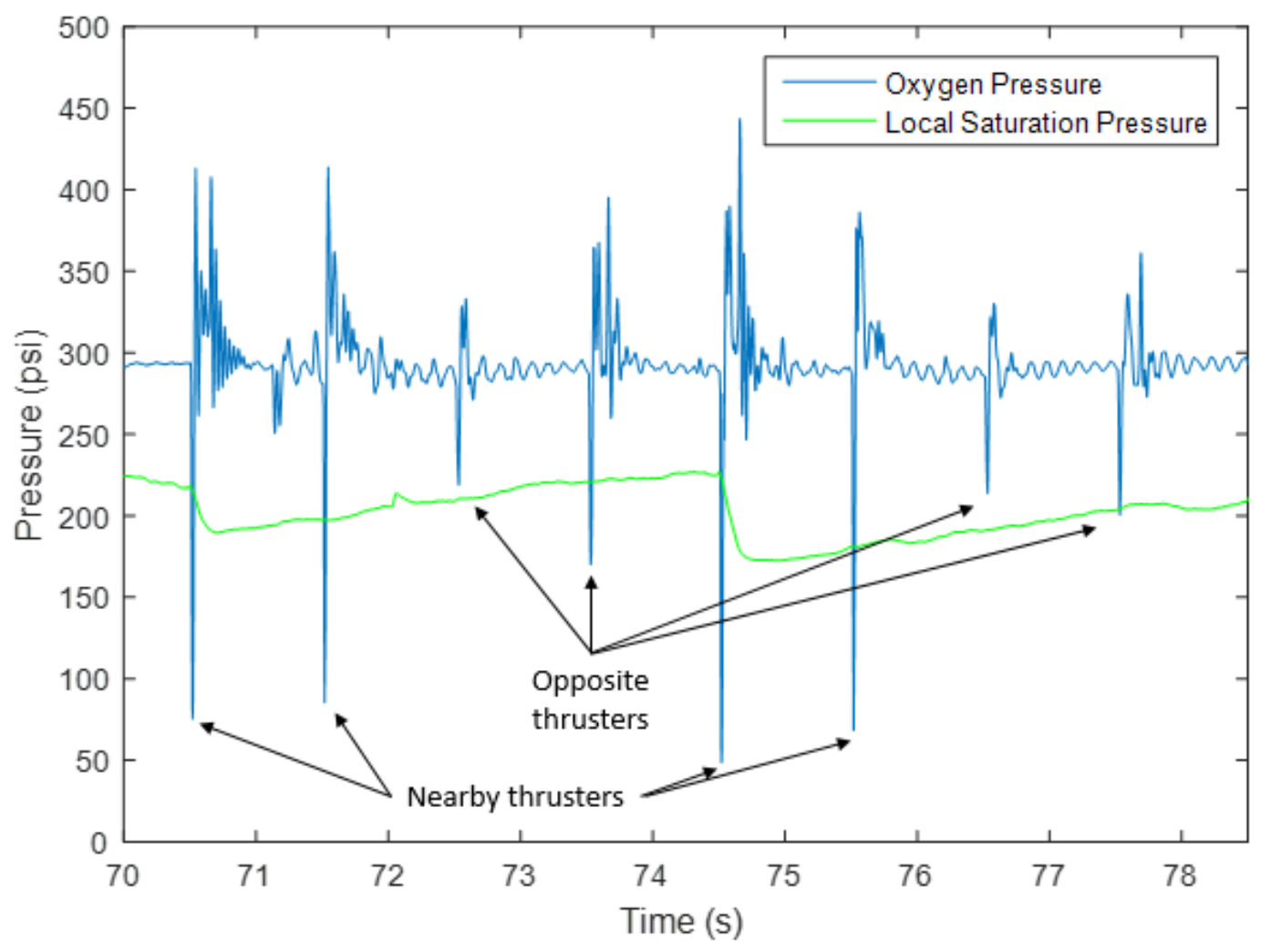

Figure 7. Measured oxygen pressure transients in which the observed trough resulting from opposite pod valve openings is near or below the local vapor pressure.

The valve opening transients were amplified even more during cold-thermal testing than during testing under ambient thermal conditions. Follow-on pressure peak amplitudes were in the 400-700 psid range for many of these pulses, with one follow-on peak measuring 900 psid above static pressure. For these tests however, the propellant in the small run upstream of the valve was subcooled liquid, not gaseous or two-phase. It is postulated that a similar phenomenon to the one described above still applies for these initial conditions. Since the flow resistance across the thruster valve is much less than the flow resistance across the injector orifices and the volume between the two is initially at vacuum when the valve opens, there is a much greater initial fluid demand across the valve than under steady state. Since the liquid farther back in the line cannot instantaneously keep up with this demand due to its inertia, a large enough trough develops to bring the propellant below its vapor pressure and cause a cavity to form. When the cavity collapses, either at the valve inlet or inside the thruster manifold, a follow-on pressure peak results.

If it is assumed that the liquid front reaches a flow rate proportional to the entire pressure drop across the valve (from supply pressure on one side to vacuum on the other) during the initial opening transient, then the resulting pressure spike using the Eq. (1) prediction will be on the order of 400 to 450 psid. Although this prediction does not 
account for all of the physical processes that are occurring (including amplification from vapor cavity collapse), it does provide a rough order of magnitude estimate for how the higher initial momentum impacts the pressure surge compared with the steady-flow initial condition for valve closing. In the cold-thermal case, the propellant is the highest density liquid with the least compliance. Because there is no two-phase propellant compressibility to dampen the initial fluid onrush as the valve opens, these transient pressure events have higher magnitude than the ambient thermal test case, even though both conditions require filling an evacuated injector manifold. A similar effect was observed for fast-valve opening sequences during some PCAD main engine altitude testing. Higheramplitude water hammer events were observed with subcooled propellants than with warmer propellants.

\section{iii. Mixture Ratio Variation}

The initial valve opening transient can create a wide range of inlet conditions for the thruster in the period leading up to ignition. This is influenced by the amplitude of the trough and follow-on peak, as discussed above, and also by the difference in frequency response between the two propellants. The natural frequency of each propellant manifold varied considerably between tests based on the initial temperature distribution. Frequencies as high as $38 \mathrm{~Hz}$ for hard liquid and as low as 7.5 $\mathrm{Hz}$ for two-phase conditions were observed on the oxygen side. These values ranged from 61 $\mathrm{Hz}$ to $15 \mathrm{~Hz}$ on the methane side. The methane side tended to respond with a higher frequency than the oxygen side for most pulses. As a result, for the typical opening transient starting at a predetermined pressure setpoint, the inlet conditions travel along a relatively constant MR to the initial trough, and then to a low MR at relatively high pressures, followed by a high $\mathrm{MR}$ as the methane pressure begins to drop again ahead of the oxygen pressure.

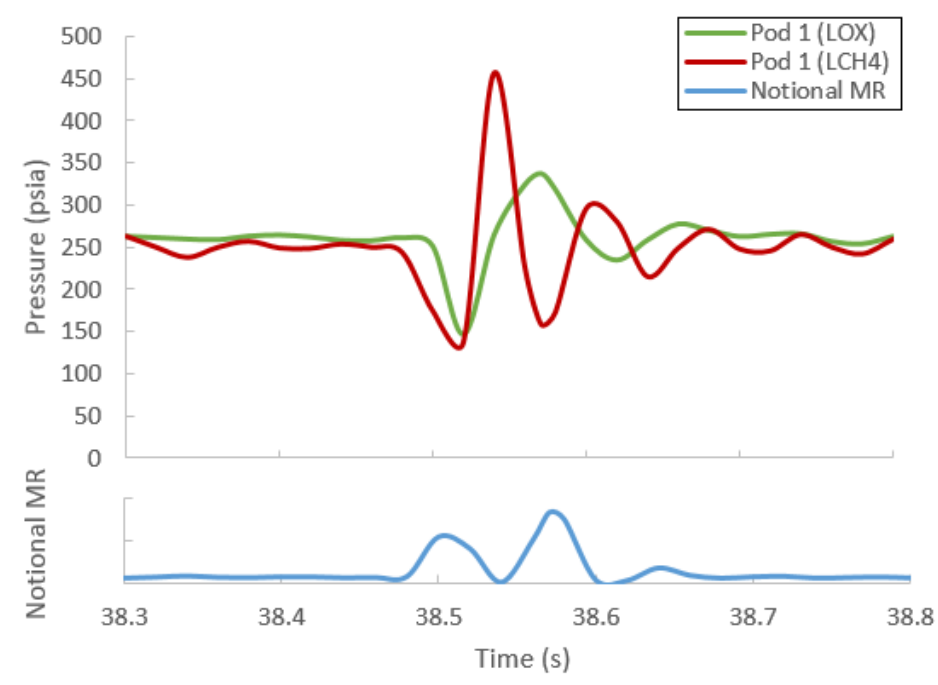

Figure 8. Example opening transient in which different natural frequencies lead to a range of inlet MR conditions during thruster startup. Note, this plot is not representative of what all opening transients looked like, but is just one example of the type of inlet pressure differences that can result.

Figure 8 shows an example opening transient of a jet firing that demonstrated a wide MR variation. Depending on the frequency difference for a given pulse (which varied widely based on conditions), a considerable time lag can occur from valve opening to when the inlet conditions reach a favorable MR zone at or above the target pressures. In a few cases, this follow-on region of higher MR was determined to coincide with the moment of ignition; however, more analysis is required to evaluate how much impact these changing conditions actually have on the ignition timing. A high-speed pressure transducer was not installed to measure chamber pressure for these tests, thus the current data do not allow for adequate characterization of how chamber pressure oscillations were influenced by the initial transient. This instrumentation would be insightful in future testing.

\section{Feed System Interaction During Simultaneous Main Engine/Reaction Control System Operation}

No simultaneous main engine/RCS tests were performed during thermal vacuum testing due to a number of issues; however, these RCS tests still provided some data on potential system level interaction. Valve closing peaks measured on the manifold were also observed at the main engine inlet pressure transducers, but at a much lower magnitude. On the oxygen side, the maximum amplitude oscillation was 8 psid for the $28 \mathrm{lbf}$-thrust engines. An example test case is shown in Figure 9. The maximum oscillation at the engine inlet was only 3 psid for the 7 lbfthrust engines. No significant oscillations were observed at the methane inlet.

During ambient-thermal testing when combined main engine/RCS testing was performed, smaller pressure oscillations were observed at the main engine inlets due to RCS engine operation. On the oxygen manifold, the maximum pressure oscillation observed due to jet operation was 3 psid. On the methane manifold, the maximum pressure oscillation was 4 psid.

These data are important for characterizing a cryogenic RCS system that shares a common manifold with the main engine since they indicate how much of an impact RCS engine operation can have on main engine operation. Results from both ambient-thermal and cold-thermal ICPTA testing indicate that this impact is negligible. 


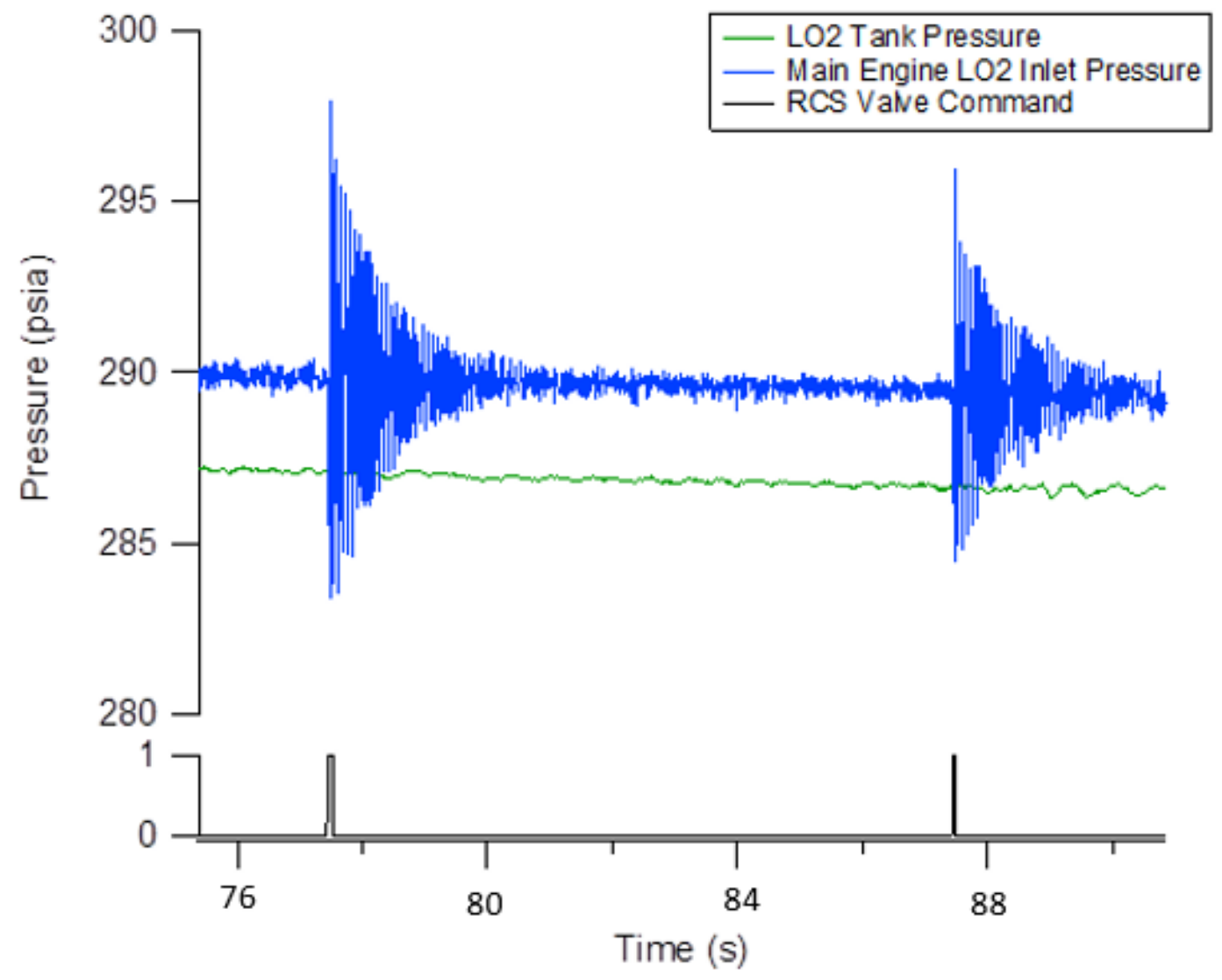

Figure 9. Pressure peaks at the main engine inlet resulting from RCS operation during cold-thermal test conditions.

\section{Results: Thruster Operation and Thermal Conditioning}

In addition to proper control of fluid transients, RCS design must also provide means with which to maintain adequate propellant conditions at the thruster inlet to allow for proper engine operation. The ICPTA data are useful to understand both RCS jet self-conditioning (i.e., no overboard bleed flow) and thermodynamic vent system (TVS) performance. The ICPTA jets are used in gas-gas, two-phase, and liquid-liquid regimes so that the trades between self-conditioning and TVS conditioning can be understood. The trades between impulse bit performance in the different operating modes can be compared to the necessary losses with overboard TVS or bleed flow.

\section{A. Self-conditioning in Ambient Temperature Environments}

On the IPCTA, the RCS includes a TVS that can be used to chill-in the manifolds leading up to the engine pods. This is valuable for situations in which the engines see a warmer environment and will heat the propellants to an undesirable operating temperature. This type of system can be designed for high efficiency, but it still results in the expenditure of propellant that could otherwise be used for attitude control. The engines on the ICPTA have demonstrated a wide operating box that includes gas-gas and two-phase operation, in addition to liquid-liquid operation (Figure 15). One mode that is potentially advantageous for an engine with this operating range is to allow it to self-condition its propellants through normal engine operation rather than controlling it to a narrow inlet temperature band with an overboard TVS. This operating concept has been demonstrated previously on a cryogenic feed-system demonstration test using liquid nitrogen as the fluid and flow simulators for the thrusters. ${ }^{11}$ In a high heat leak environment where low control authority is required, the engine would operate gas-gas or two-phase. This would result in a lower MIB which can be advantageous under certain attitude control scenarios (e.g. when maintaining attitude within a deadband). If a higher control authority is needed, higher duty cycle pulsing will result in the manifolds chilling in sufficiently to provide for liquid-liquid operation. The key to this operating mode is ensuring that the transient conditions remain within the engine's allowable operating range and that vehicle's control system can handle the variable MIB. 


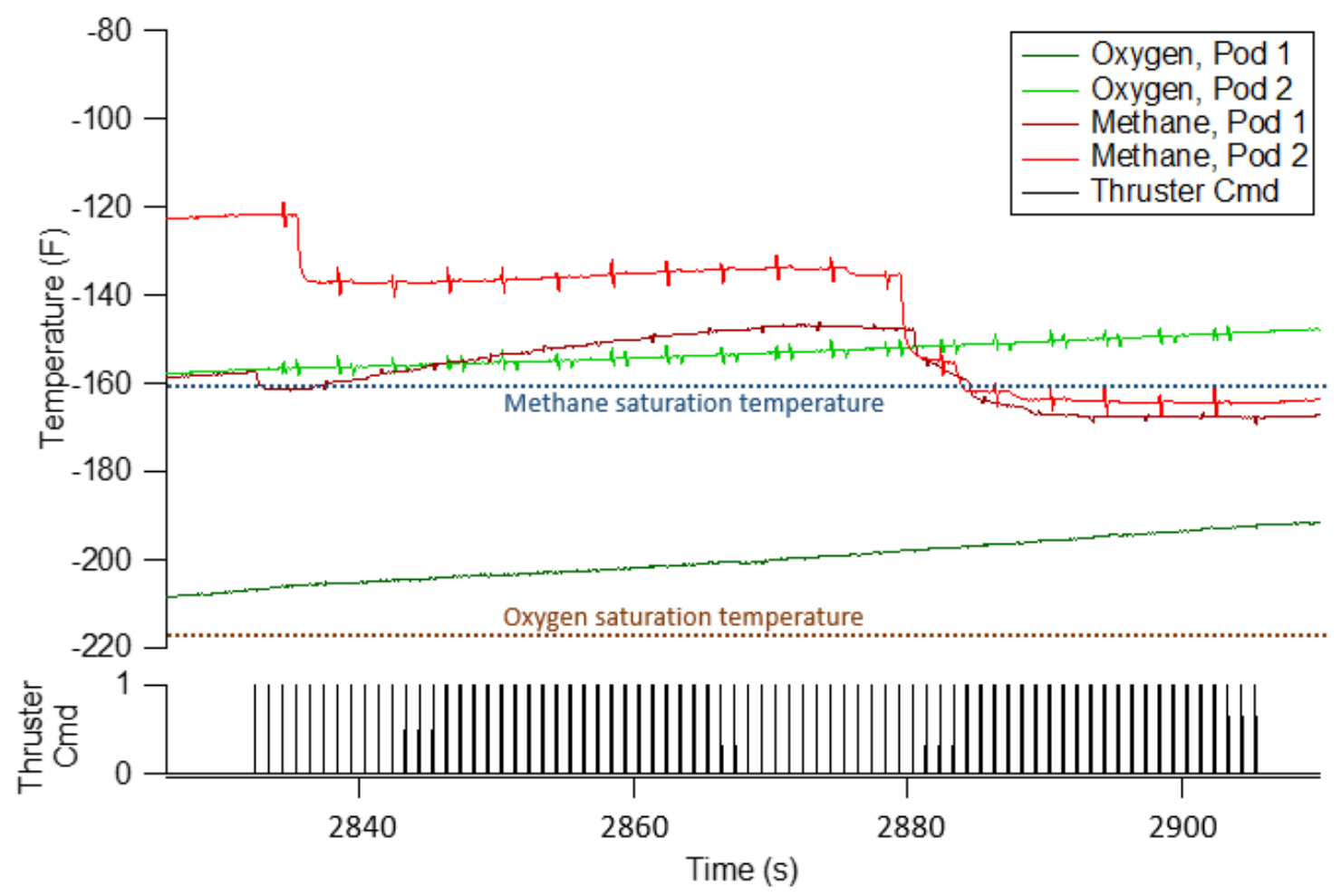

Figure 10. Manifold skin temperature near the thruster inlets for a pulsing sequence in which methane manifold reaches liquid conditions but the oxygen manifold does not.

Multiple test sequences were performed without active TVS to examine how the thruster inlet conditions changed with different duty cycles. One example of a sequence in which the engines partially chilled in as a result of thruster operation only is shown in Figure 10. The sequence consisted of one 80 ms pulse per jet every 4 seconds, with each jet position firing in 1-second intervals (i.e., the jet sequence repeats every 4 seconds). During this test the inlet manifold temperatures (measured by a skin thermocouple near the thruster valve inlets) initially read gaseous propellant temperatures. After approxomiately 60 seconds of pulsing the two methane temperatures drop rapidly to values below the saturation temperature, indicating that liquid has been drawn up the manifold to the engine inlet. On the oxygen side, the temperature sensors continue to show gaseous conditions for the entirety of the test. For tests in which both manifolds started with gaseous temperatures well back into the manifold, methane consistently chilled in prior to oxygen. This is beneficial since the ICPTA engines can operate successfully with liquid methane and two-phase oxygen, but will overheat if operated on liquid oxygen and two-phase methane.

In another test during higher duty cycle operation, the high propellant demand was able to keep both propellant inlets at liquid conditions during valve operation. Test data for the submerged thermocouples just upstream of the valve inlets are shown in Figure 11. Although the inlet conditions start as gaseous or saturated on both propellants, the temperatures quickly reach liquid condition values once rapid pulsing starts, and remain there until pulsing stops. This repeats for several sequences, with the temperature that the manifold warms back to decreasing over time. These higher duty cycles can stress the engines thermally; however, even for this test in which the oxygen manifold started closer to liquid conditions, the engines still remained below their redline temperature limits. 


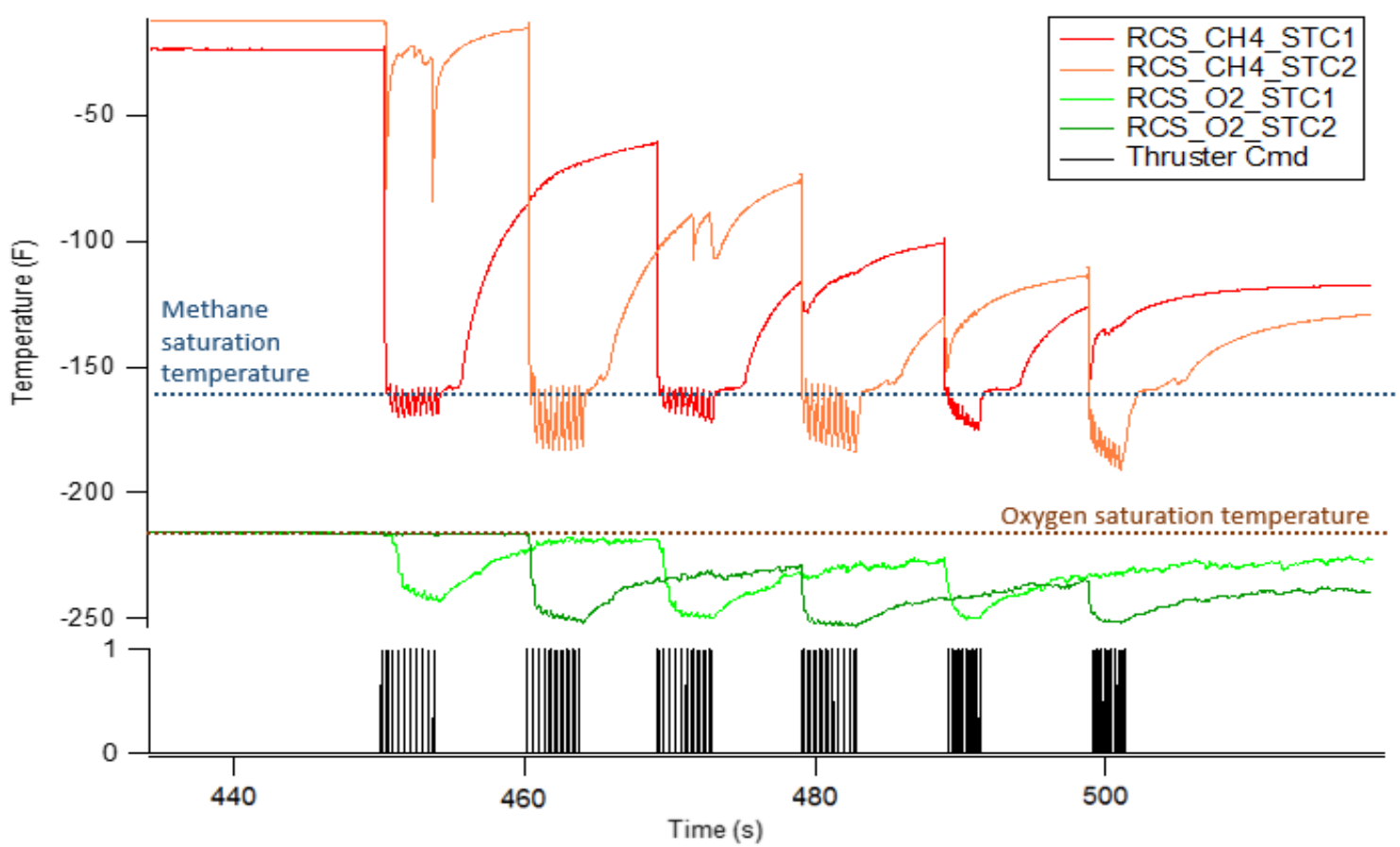

Figure 11. Submerged thermocouple data for high duty cycle test where liquid conditions are reached.

\section{B. Self-Conditioning in Cold-Thermal Environments}

The test conditions described above presented a relatively high heat leak compared with a typical spacecraft operating environment. Although the test cases run in this segment did not tease out every gas-to-liquid transition for the manifolds and engines, they did demonstrate the feasibility of operating the jets through that regime without active conditioning. On the other end of the heat leak spectrum was thermal vacuum testing, in which the test article was allowed to reach steady thermal conditions prior to engine operation. The thruster bodies and associated hardware reached steady values between $-200{ }^{\circ} \mathrm{F}$ and $-225^{\circ} \mathrm{F}$ during the long duration cold soak. All measured oxygen and methane manifold temperatures near the thruster pods measured approximately the same as the thruster bodies. As soon as the system was pressurized prior to the first test, all manifold temperatures dropped as subcooled propellant was forced out to the ends of the manifolds. Measured propellant temperatures remained highly subcooled for the remainder of the test day without any significant effort to maintain the conditions other than pulsing the engines. The effect of the cold-thermal environment for a set of MIB pulses is shown in Figure 12. Neither manifold experienced any significant change in temperature. In this heat leak environment, no conditioning was required to reach liquid conditions throughout the manifolds, and TVS operation was not required to maintain subcooled liquid conditions at the thruster inlets.

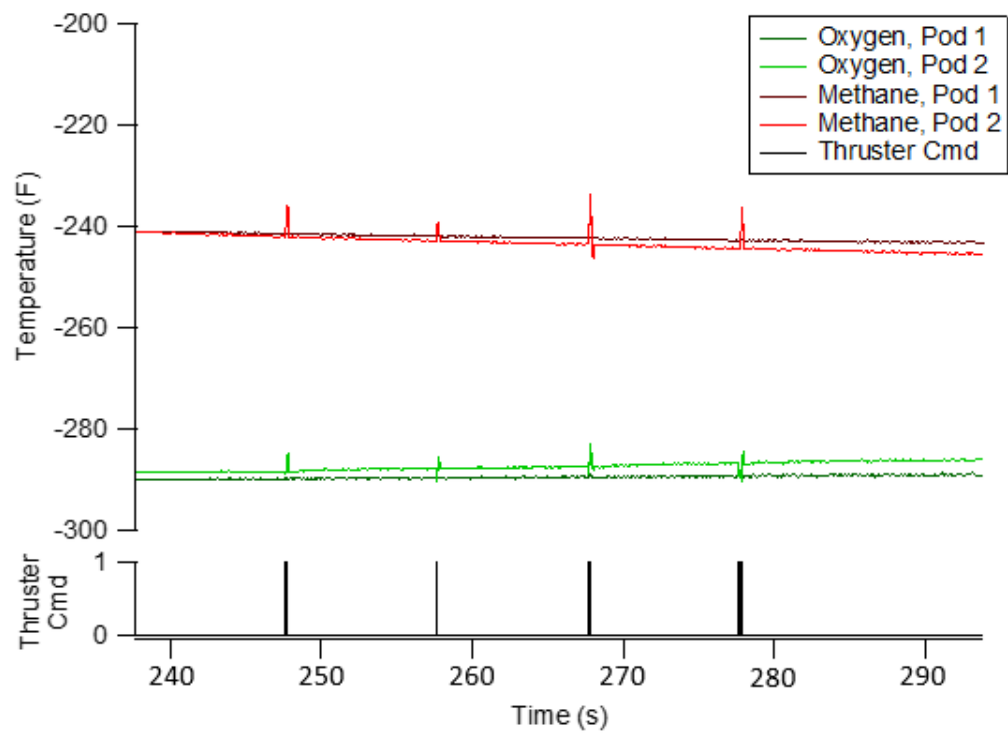

Figure 12. Submerged thermocouple data for pulsing in cold-thermal wall conditions (ambient temperature less than $-200{ }^{\circ} \mathrm{F}$.

American Institute of Aeronautics and Astronautics 


\section{Thermodynamic Vent System Performance}

For many test cases in the ambient thermal environment, the TVS was used to condition the engines to a more specific operating point prior to a test. In a partial self-conditiong scheme, the TVS could be used to speed up the initial transient to the needed operating condition (e.g. before a lander descent phase) or to make sure the two propellant temperatures do not violate an acceptable inlet condition range. One test in which the TVS was used to maintain the propellants at their saturation temperature is shown below in Figure 13. During this 10-minute test, an 80 -ms pulse was performed every 60 seconds on jet 4, with the TVS set to control the thruster inlets to within $10^{\circ} \mathrm{F}$ of each propellant's saturation temperature. The thrusters do not provide any cooling to maintain the manifold conditions at such a low operating rate. In this mode, the TVS operated multiple times per minute, and the oxygen manifold required more on/off cycles to maintain this level of cooling than the methane manifold. Toward the end of this test the methane pod 1 temperature begins to rise. This is due to higher heat leak on that side of the methane manifold (this was consistently observed throughout testing) in addition to the TVS only controlling to the pod 2 set point since there was no jet firing on pod 1.

In another test, shown in Figure 14, the propellants were brought to liquid conditions before the test, and the TVS remained active with an oxygen setpoint of $-250{ }^{\circ} \mathrm{F}$ and a methane setpoint of $-190^{\circ} \mathrm{F}\left(10^{\circ} \mathrm{F}\right.$ allowable temperature band). This test consisted of a series of paired 0.5 -second pulses in which two engines from the same pod would fire simultaneously. Four oxygen TVS on/off cycles are required during the 20 -second test to maintain the Pod 1 oxygen temperatures near the setpoint (Pod 2 does not warm as quickly). Only one methane TVS cycle is required to keep the two methane pods within the acceptable temperature band during the same time. These TVS setpoints were the same used to maintain adequate control authority during free flight operations when the RCS system was used for roll control during the Morpheus flight test campaign in 2014.

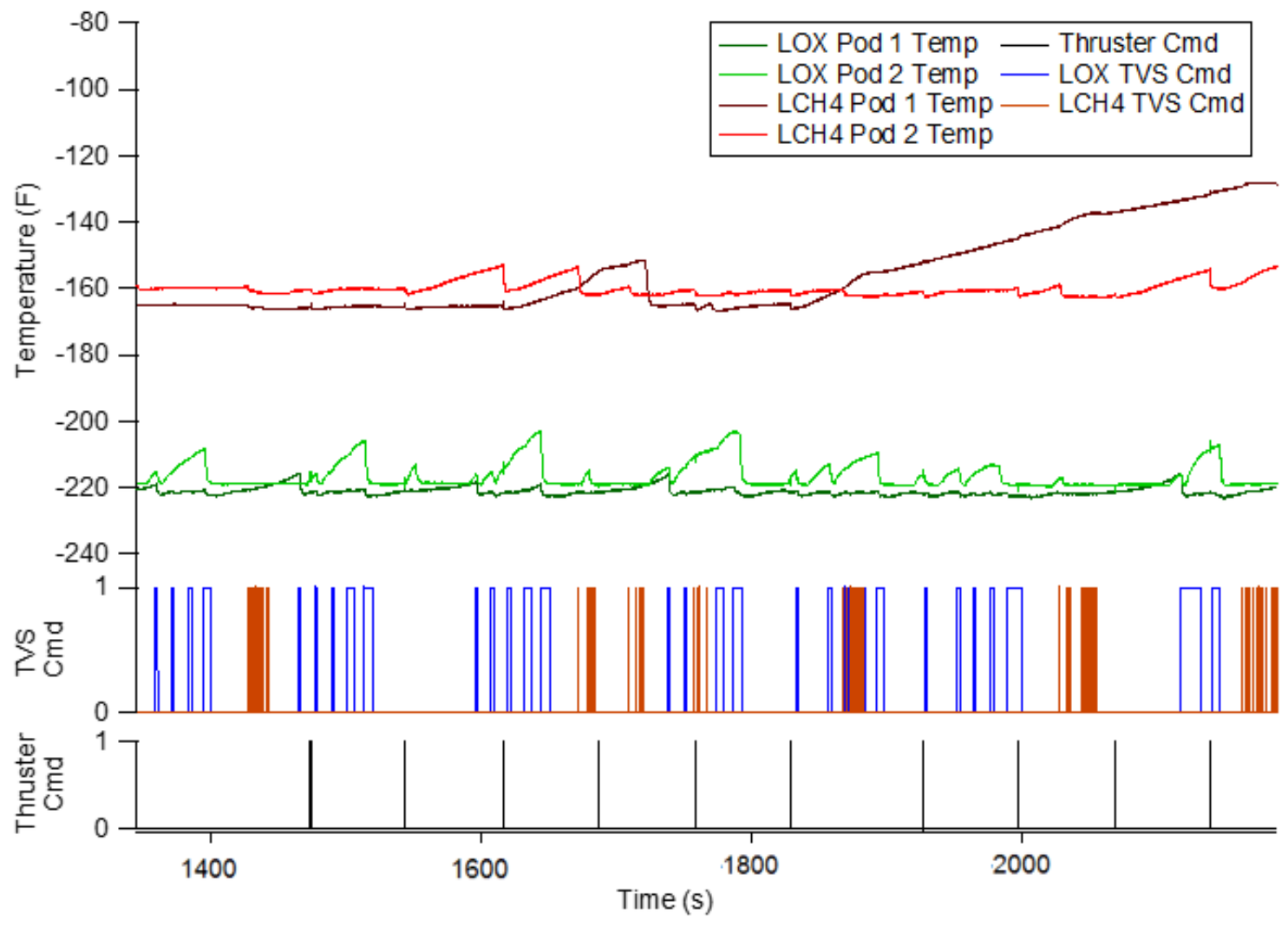

Figure 13. TVS operation during a 10-minute duration test with 80-ms thruster firings every 60 seconds. Temperature control band for oxygen is set to $-220{ }^{\circ} \mathrm{F}$ to $-200{ }^{\circ} \mathrm{F}$, and $-165^{\circ} \mathrm{F}$ to $-150{ }^{\circ} \mathrm{F}$ for methane. 


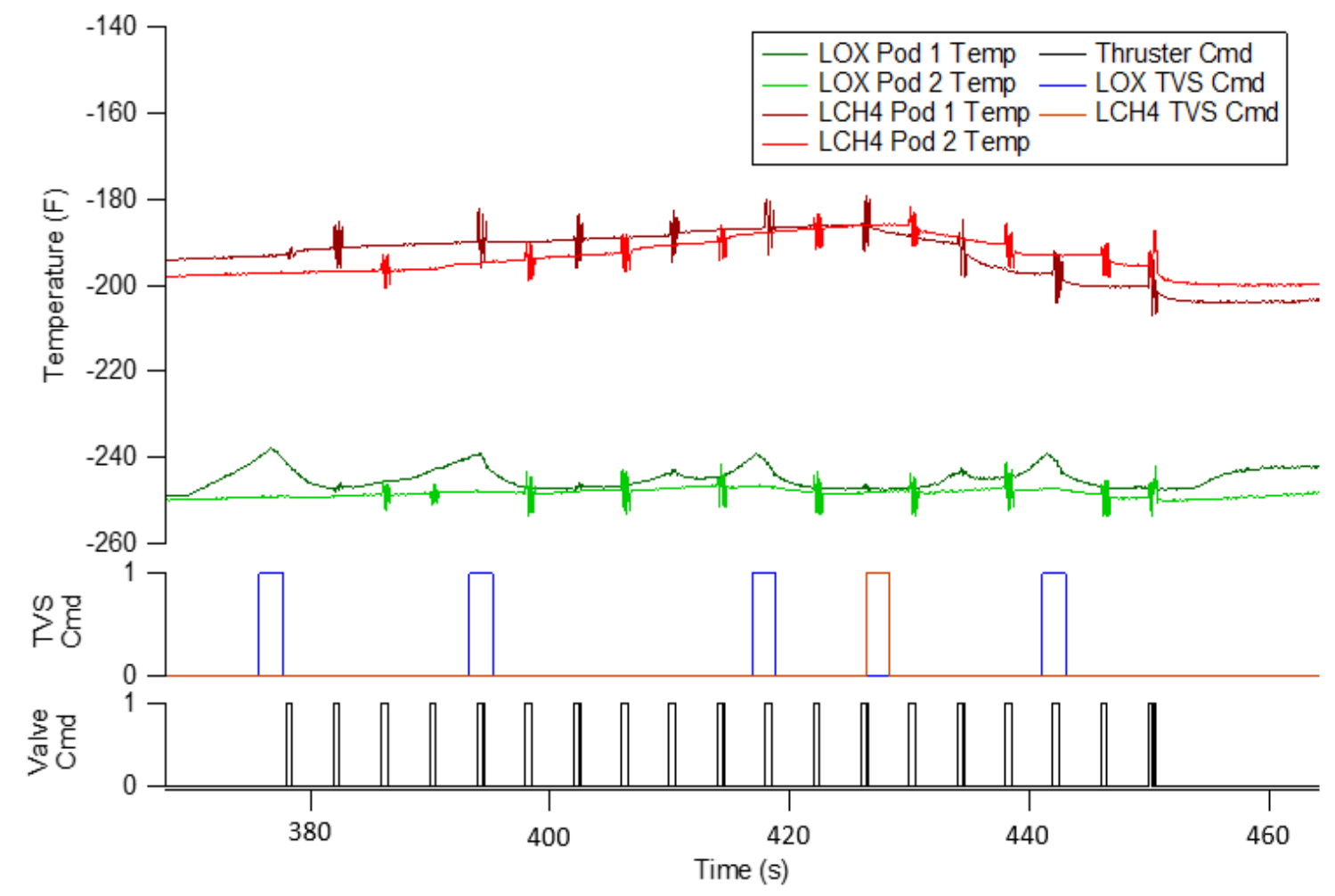

Figure 14. TVS operation for liquid-liquid pulsing sequence in which sets of 0.5 -second paired pulses are performed with different jet combinations every 4 seconds. TVS setpoints are $-250{ }^{\circ} \mathrm{F}$ for oxygen and $-190{ }^{\circ} \mathrm{F}$ for methane (with $+/-10^{\circ} \mathrm{F}$ control band).

It should be noted that since all testing was performed with test cell conditions above 1 torr, MLI performance was relatively poor, which in turn drove higher TVS consumption rates. To characterize how effective the TVS orifice flow was at cooling the manifolds, a long-duration methane TVS test was performed in which the entire manifold started at approximately $-50^{\circ} \mathrm{F}$. The TVS valve was opened and allowed to flow until liquid conditions were obtained at the TVS outlet. The thermal mass of the plumbing from the main feedline tap-off location to the TVS outlet is approximately $0.54 \mathrm{BTU} /{ }^{\circ} \mathrm{F}$. It took 300 seconds after flow initiation for all manifold thermocouples to reach a steady temperature of $-215^{\circ} \mathrm{F}$. This equates to an average heat removal rate of approximately $0.3 \mathrm{BTU} / \mathrm{s}$ (316 Watts). Heat leak into the propellant manifolds was estimated by looking at the temperature rise between TVS valve cycles for a representative line segment. The segment had constant insulation and external view factor, and a skin thermocouple at its center was used to measure temperature rise. For the methane manifold in ambient-thermal testing, the local heat leak estimate based on this segment was $9 \mathrm{~W}$. If extrapolated to the whole manifold, the overall heat leak would be approximately $101 \mathrm{~W}$.

\section{Thruster Ignition Mapping with Inlet Conditions}

In Figure 15 all 1,010 pulse attempts are mapped to the corresponding oxygen and methane inlet temperatures. The oxygen propellant tank pressure was always between 5 and 15 psi above the methane propellant tank pressure for these tests, resulting in a relatively narrow operating range for this comparison. Although these tests were not intended to serve as an ignition reliability demonstration, the map is indicative of where improvements to the operating box are required. A large amount of the no-lights (or partial igntions as later found) are clustered below $210{ }^{\circ} \mathrm{F}$ for methane and $-270{ }^{\circ} \mathrm{F}$ for oxygen. These correspond with the cold-thermal test conditions, in which the thruster bodies were much colder than during ambient-thermal testing. 


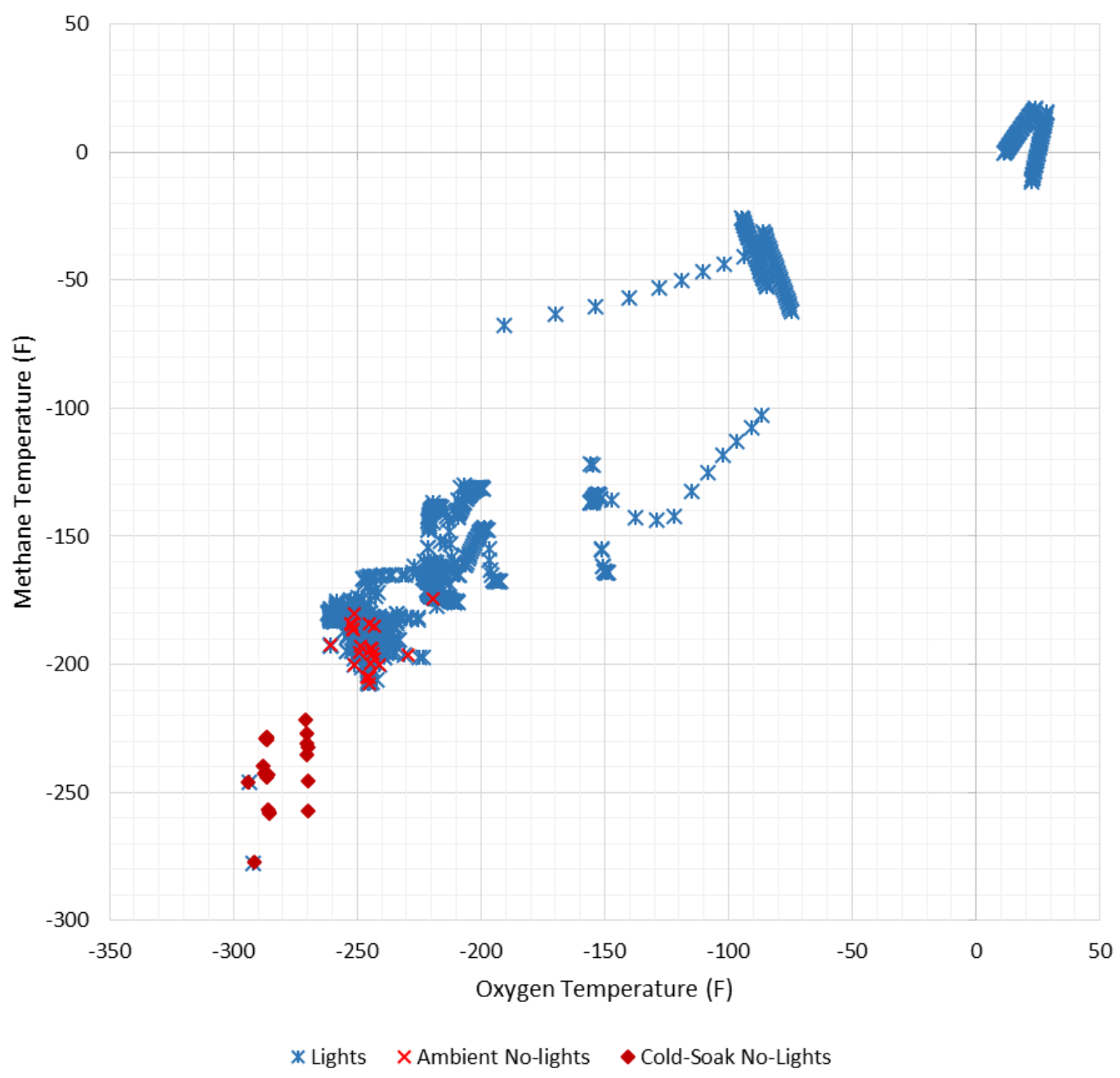

Figure 15. Inlet temperature map showing every light and no-light for set pressures in which oxygen was 5-15 psia higher than methane. Data for both 28 lbf-thrust and 7 lbf-thrust engines are shown.

Overall, results show that the thruster jets ignited repeatably at gas-gas conditions, two-phase conditions, saturated liquid-liquid, and liquid-oxygen/gaseous methane conditions. For liquid-liquid operation, the majority of no-lights in the ambient-thermal environment are attributed to pulse length (too short) or improper conditioning (too cold on methane) This operational limit had been previously observed in sea-level testing at both the componentlevel and integrated vehicle testing. The remaining no-lights (or partial ignitions) were observed when the test cell operated in the cold thermal environments, as discussed in the next section.

\section{E. Thermally-Induced Non-Ignitions/Partial Ignitions}

During thermal vacuum testing there was considerable difficulty igniting the engines. Out of 23 attempts, only two were successful. Each pulse attempt was $80 \mathrm{~ms}$ in duration, and attempts were made with both the $7 \mathrm{lbf}$-thrust and $28 \mathrm{lbf}$-thrust engines. As a comparison, during simulated altitude testing under ambient thermal conditions, 817 out of 832 pulse attempts of this duration or shorter resulted in successful ignition. 
A camera was positioned looking up the throat of one $28 \mathrm{lbf}$ thrust jet such that the initial transient could be seen across two to four frames. In every no-light on this engine, a small ignition event is clearly visible before it is extinguished and the pulse becomes a cold flow. An example sequence is shown in Figure 16. Similar camera angles were not available for the other two engines that were operated under these conditions, so it is not known whether this same event occurred
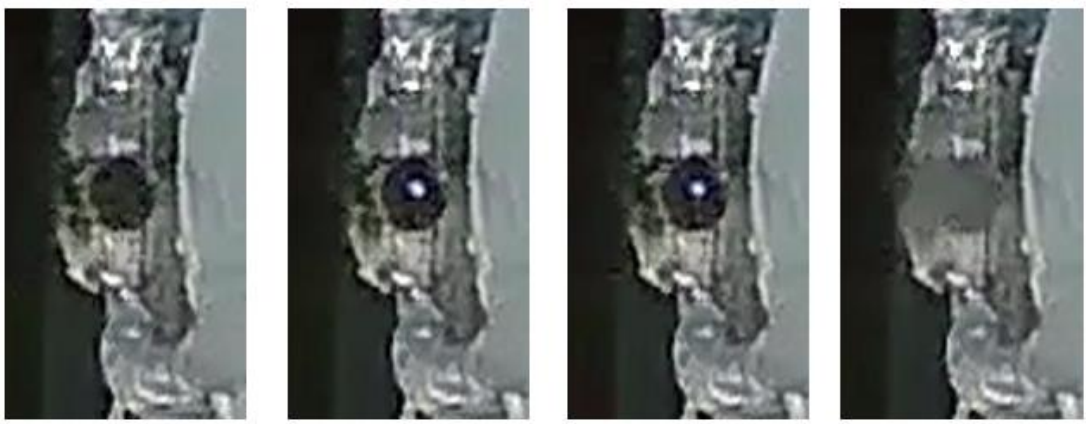

Figure 16. Frame-by-frame sequence showing core ignition followed by quenching from film cooling for Jet 3 "no-light" in cold-thermal environment. for other no-lights.

A number of contributing factors might have influenced the poor ignition characteristics. First, a much lower cold flow pressure was observed in the thermal testing due to the lower propellant and thruster body temperatures. This is due to a reduced vapor pressure at these propellant temperatures combined with a large reduction in heat transfer to the propellants from the cold thruster bodies as they travel through the injector manifold, resulting in little to no additional vaporization. The $28 \mathrm{lbf}$-thrust engine had an average cold flow pressure of 5.7 psi compared with approximately 20 psi during ambient thermal testing, and the $7 \mathrm{lbf}$-thrust engine had an average cold flow pressure of 19 psi compared with approximately 60 psi during ambient thermal testing. These lower cold flow pressures potentially contribute to the conditions that lead to the quenching observed in Jet 3 , since a higher percentage of

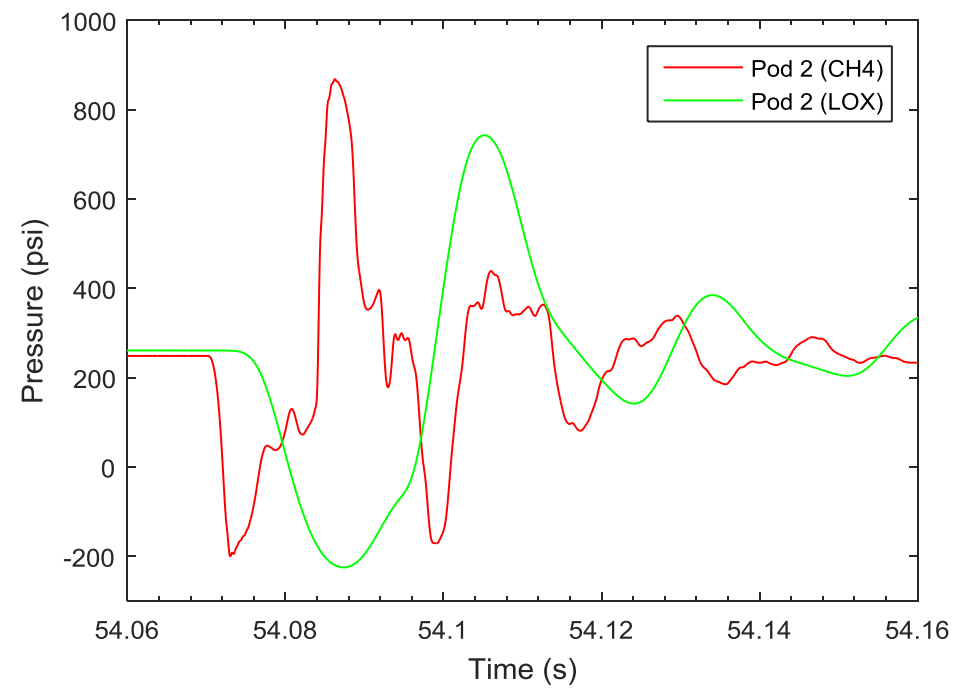

Figure 17. Valve opening transient for $80 \mathrm{~ms}$ pulse on 7 lbf-thrust engine under cold soak conditions. ignition combustion energy in the chamber is lost to the walls and film cooling.

The engines are tuned to operate at a low overall MR due to material limitations. A high MR core promotes ignition, with a significant amount of fuel film cooling injected farther downstream in the chamber. The film cooling brings the overall engine MR to a value well below stoichiometric (this was done to allow for unlimited operation in high duty-cycle regimes), and during some transients it is possible for the MR to drop below the flammability limit for oxygen and methane. Since the chamber body is significantly colder in the cold-thermal testing, the fuel film cooling that enters the chamber during the ignition transient is also colder and denser. This dense film cooling can help to quench the core by pulling energy away from the initial flame kernel. Denser film cooling can also potentially reduce the MR below the flammability limit during the transient. Improvements in the cold-thermal environment will likely be obtained by tuning the engines to operate at a higher overall MR.

Valve opening transients also possibly played a role in the ignition behavior by creating wide MR swings into a region unfavorable for ignition. As mentioned above, the opening fluid pressure transient tended to be more severe under cold soak conditions. Each pulse had a very similar transient profile under these conditions. An example for one 80-ms pulse on the $7 \mathrm{lbf}$-thrust engine is shown in Figure 17 . As a result of the frequency mismatch, the initial methane peak aligns with the oxygen trough, creating a period of roughly $20 \mathrm{~ms}$ in which the MR is below an ignitable range. The following half-period results in a swing to a higher MR region in which conditions should be favorable for ignition. These fluctuations may have an impact on the ignition transient, especially for shorter pulses. 
Ignition energy can be another common culprit. Benchtop testing showed that the COP units for these engines produce 22 to $24 \mathrm{~mJ}$ of spark energy at 100 sparks per second. ${ }^{8}$ A significant amount of component-level and vehicle tests demonstrated that this was enough to light the engines under ambient thermal conditions. Since the videos of Jet 3 indicate ignition of the core is occurring even under the cold conditions, it seems evident that the $\mathrm{COP}$ is generating sparks with enough energy to light the engine; therefore, this is not considered a likely reason for the ignition problems. Because all of the pulses during cold-thermal testing were short duration, it is possible that extending the spark duration out past the commanded valve closure time could have improved the probability of achieving a favorable MR for ignition. This was tried with success in the past, ${ }^{5}$ but was not possible during Plum Brook testing based on the valve driving scheme.

It should be noted that the two jet pulses that successfully lit in the cold-thermal environment occurred following a gaseous nitrogen purge that warmed the jet body temperatures. During ambient-thermal environment testing, jet body temperatures were approximately $0{ }^{\circ} \mathrm{F}$ (or warmer). However, in the cold-thermal environment testing, the jet body temperatures fell below $-275^{\circ} \mathrm{F}$ once the system was pressurized with liquid propellant onboard. Figure 18 shows the jet nozzle temperatures measured during the cold-thermal environment testing. The system was pressurized at a time of approximately 40 minutes on the plot, and this coincides with when the body temperatures begin to drop. The six test sequence attempts are labeled T1-T6. The first four tests were attempted without any conditioning of the jet bodies (T1-T4), and these tests all took place with body temperatures below $-275^{\circ} \mathrm{F}$. After these four unsuccessful attempts, a warm gaseous nitrogen purge was used to warm the thruster bodies for attempts at higher temperatures. Test 5 occurred at a thruster body temperature of $-218^{\circ} \mathrm{F}$ on jet 3 , and resulted in three more no-lights. For Test 6 , the body temperatures for jets 1 and 4 were increased to $-140^{\circ} \mathrm{F}$ and $-161^{\circ} \mathrm{F}$, respectively. Each engine demonstrated one successful ignition under these warmer body conditions.

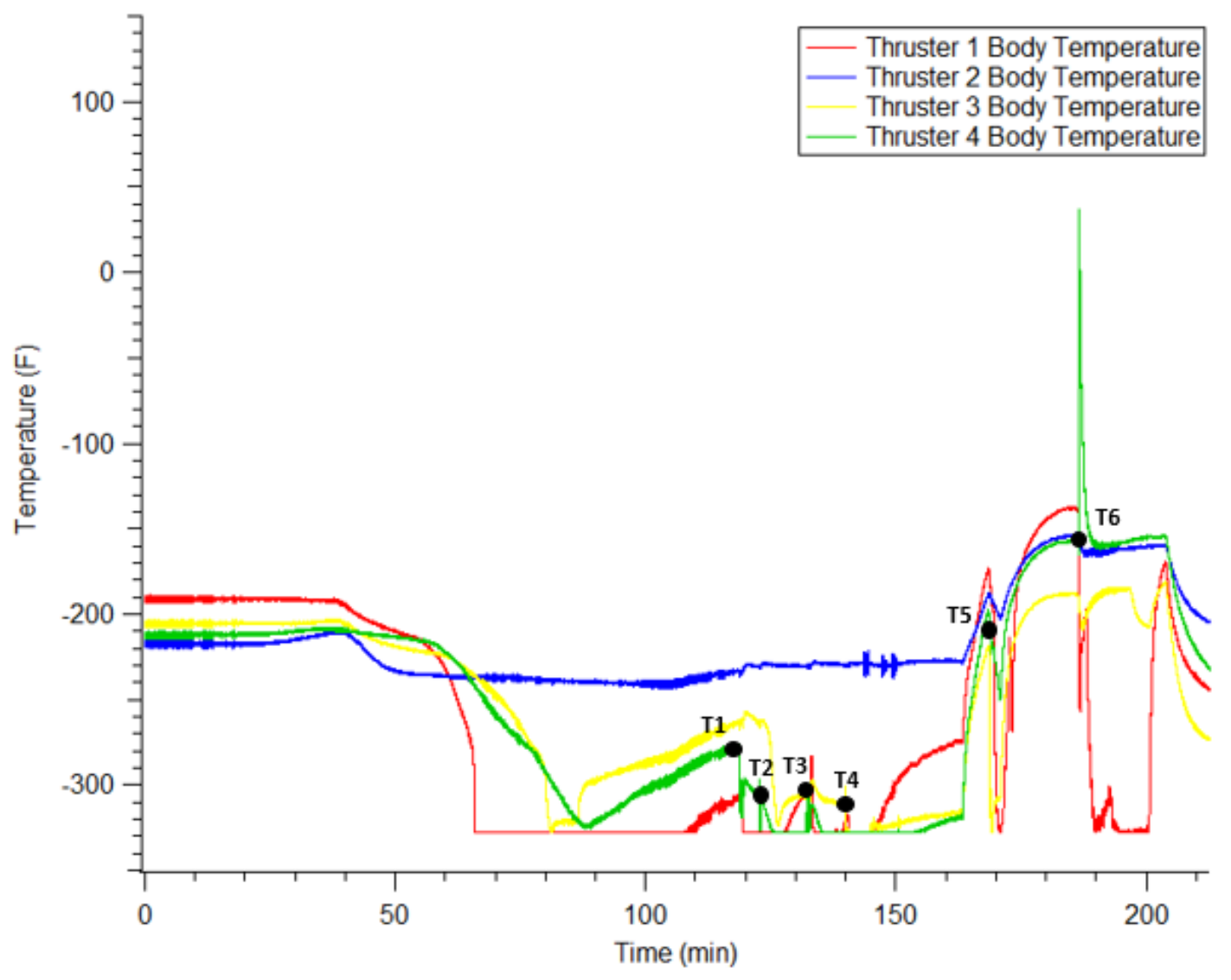

Figure 18. Jet body temperatures during cold soak testing, measured by Type $K$ thermocouples welded to the nozzle throats.

Further cold-thermal environment testing was suspended after the Test 6 pulses due to a mechanical failure on one of the COP igniters and other ICPTA vehicle-level leakage issues. The cold-thermal environment ignition function remains an open item for future work. Note that previous testing during PCAD had used very cold 
propellants; however, no testing had previously been conducted where the jet body was allowed to reach coldthermal conditions.

\section{F. Test Matrix}

A summary of RCS tests is presented in Table 2 .

Table 2: Summary RCS Test Matrix

\begin{tabular}{|c|c|c|c|c|c|}
\hline $\begin{array}{l}\text { Test } \\
\text { Number }\end{array}$ & Test Description & $\begin{array}{c}\text { Environment } \\
\text { (Pressure/Thermal) }\end{array}$ & Propellant Conditions & TVS Used? & Ignitions \\
\hline 1 & Various $1-2$ sec pulses & Altitude/Ambient & Liquid & Yes & $4 / 4$ \\
\hline 2 & Various $1-2$ sec pulses & Altitude/Ambient & Liquid & Yes & $4 / 4$ \\
\hline 3 & Various $1-2$ sec pulses & Altitude/Ambient & Liquid & Yes & $8 / 8$ \\
\hline 4 & Various 1-2 sec pulses with ME operation & Altitude/Ambient & Liquid & Yes & $4 / 4$ \\
\hline 5 & Various 1-2 sec pulses with ME operation & Altitude/Ambient & Liquid & Yes & $3 / 4$ \\
\hline 6 & Various 1-2 sec pulses with ME operation & Altitude/Ambient & Liquid & Yes & $4 / 6$ \\
\hline 7 & Low duty cycle MIB pulsing & Altitude/Ambient & Liquid & Yes & $18 / 20$ \\
\hline 8 & Low duty cycle MIB pulsing & Altitude/Ambient & Liquid & Yes & $20 / 20$ \\
\hline 9 & Low duty cycle MIB pulsing & Altitude/Ambient & Gasesous & No & $19 / 20$ \\
\hline 10 & Low duty cycle MIB pulsing & Altitude/Ambient & Gasesous & No & $75 / 75$ \\
\hline 11 & Low duty cycle MIB pulsing & Altitude/Ambient & Gaseous to Two-phase & No & $74 / 74$ \\
\hline 12 & Low duty cycle MIB pulsing & Altitude/Ambient & Gaseous to Two-phase & No & $74 / 74$ \\
\hline 13 & Low duty cycle MIB pulsing & Altitude/Ambient & Two-phase & Yes & $75 / 75$ \\
\hline 14 & Methane TVS Test & Altitude/Ambient & Gaseous to Liquid & Yes & $0 / 0$ \\
\hline 15 & Low duty cycle MIB pulsing & Altitude/Ambient & Two-phase & No & $20 / 20$ \\
\hline 16 & Low duty cycle MIB pulsing & Altitude/Ambient & Liquid & No & $20 / 20$ \\
\hline 17 & Low duty cycle MIB pulsing & Altitude/Ambient & Two-phase & Yes & $65 / 74$ \\
\hline 18 & $0.5 \mathrm{sec}$ pulses, staggered and simo shutdown & Altitude/Ambient & Liquid & Yes & $34 / 36$ \\
\hline 19 & Low duty cycle MIB pulsing & Altitude/Ambient & Two-phase & No & $78 / 78$ \\
\hline 20 & 5 second steady-state pulse & Altitude/Ambient & Liquid & No & $1 / 1$ \\
\hline 21 & Various $0.1-2$ sec pulsing & Altitude/Ambient & Liquid & Yes & $4 / 4$ \\
\hline 22 & Various $0.1-2$ sec pulsing & Altitude/Ambient & Liquid & Yes & $35 / 35$ \\
\hline 23 & Various $0.1-2$ sec pulsing & Altitude/Ambient & Liquid & Yes & $14 / 14$ \\
\hline 24 & Various $0.1-2$ sec pulsing with ME operation & Altitude/Ambient & Liquid & Yes & $0 / 0$ \\
\hline 25 & Various $0.1-2$ sec pulsing with ME operation & Altitude/Ambient & Liquid & Yes & $14 / 14$ \\
\hline 26 & Low duty cycle MIB pulsing & Altitude/Ambient & Two-phase & No & $52 / 52$ \\
\hline 27 & Low duty cycle MIB pulsing & Altitude/Ambient & Two-phase & No & $7 / 7$ \\
\hline 28 & Low duty cycle MIB pulsing & Altitude/Ambient & Two-phase & No & $15 / 16$ \\
\hline 29 & Long duration MIB pulsing & Altitude/Ambient & Gaseous & No & $20 / 20$ \\
\hline 30 & Long duration MIB pulsing & Altitude/Ambient & Two-phase & Yes & $20 / 20$ \\
\hline 31 & High duty cycle pulsing & Altitude/Ambient & Liquid & Yes & $120 / 120$ \\
\hline 32 & Steady state + high duty cycle pulsing & Altitude/Ambient & Liquid & Yes & $19 / 19$ \\
\hline 33 & Various 0.080 to $1 \mathrm{sec}$ pulsing & Altitude/Ambient & Liquid & Yes & $7 / 8$ \\
\hline 34 & Various 0.080 to $1 \mathrm{sec}$ pulsing & Altitude/Ambient & Liquid & Yes & $31 / 36$ \\
\hline 35 & Low duty cycle MIB pulsing & Vacuum/Cold Soak & Liquid & No & $0 / 5$ \\
\hline 36 & Low duty cycle MIB pulsing & Vacuum/Cold Soak & Liquid & No & $0 / 2$ \\
\hline 37 & Low duty cycle MIB pulsing & Vacuum/Cold Soak & Liquid & No & $0 / 5$ \\
\hline 38 & Low duty cycle MIB pulsing & Vacuum/Cold Soak & Liquid & No & $0 / 4$ \\
\hline 39 & Low duty cycle MIB pulsing & Vacuum/Cold Soak & Liquid & No & $0 / 3$ \\
\hline 40 & Low duty cycle MIB pulsing & Vacuum/Cold Soak & Liquid & No & $2 / 3$ \\
\hline
\end{tabular}




\section{Conclusions}

The work represented here is directly applicable to future LOX/LCH4 spacecraft propulsion system design and testing, and represents the first thermal vacuum testing of an integrated cryogenic RCS. Key observations include feed system dynamics for engine operation and priming, propellant conditioning with and without TVS operation, and ignition mapping for various inlet conditions:

RCS Feed System Dynamics:

- Priming pressure peak amplitudes were 2.6 to 2.9 times the upstream supply pressure for the oxygen manifold and 1.4 to 2.1 times the upstream supply pressure on the methane manifold. Thermocouples indicated that the amplitude was dampened by only gaseous-phase propellant reaching the ends of the manifolds.

- Water hammer during valve closing matched reasonably well with the analytical prediction of peak pressure amplitude for an instantaneous valve closure and compressible fluid.

- Pressure peak amplitudes were consistently higher for valve openings than valve closings. This is postulated to be the result of vapor cavity formation and collapse at the thruster inlet and in the thruster manifold.

- Water hammer during engine valve openings can lead to a wide variation in MR during the ignition transient due to the difference in natural frequency between the oxygen and methane manifolds.

- RCS feed system transients had very little impact on main engine inlet conditions, with less than 10 psid amplitude waves at the main engine manifold during cold thermal-environment testing.

- Higher peak pressure amplitudes were observed during cold-thermal test conditions, likely as a result of the less compliant fluid environment in the propellant manifolds (hard liquid propellant versus some two-phase).

Propellant Conditioning:

- Under ambient-thermal conditions, self-conditioning was demonstrated to be a feasible mode for maintaining liquid or near-liquid conditions at the thruster inlets, but this required high duty cycles.

- Engine operation at lower duty cycles can still maintain the manifolds at conditions near the saturation temperature for each propellant. This can be favorable in some mission phases due to the smaller gas-gas MIB.

- TVS operation can supplement the self-conditioning operating mode by providing added heat rejection capability for high heat leak environments or missions phases in which more control authority is required immediately.

- Under cold-thermal conditions, no TVS operation was required to maintain subcooled liquid conditions at the thruster inlets.

Thruster Ignition / Performance:

- No significant variation in ignition behavior was observed between ambient-thermal vacuum testing and sealevel checkout testing. No-lights that did occur were attributed to propellant conditioning or short pulse length.

- Engine operation was demonstrated with propellant manifold conditions ranging from gas-gas to two-phase to liquid-liquid.

- During cold-thermal testing, a considerable drop in engine ignitability was observed. This is attributed to quenching of the core as a result of colder thruster bodies reducing the cold flow pressure and increasing film cooling density.

- Successful ignition was demonstrated in cold-thermal testing after warming the thruster bodies with a nitrogen purge flow.

At the end of the NASA PCAD program, thermal-environment testing was identified as a key forward task. ${ }^{1}$ This study made significant progress into understanding cryogenic RCS operation in a thermal vacuum environment; however, more effort is still needed to investigate many of the issues that arose during cold-thermal testing. These results indicate that performance testing with cold hardware (if that condition is within the expected operating envelope) is critical to understanding how the hardware will behave.

Forward work will include additional engine testing as well as validation of thermal/fluid models. Engine-level thermal vacuum testing must be performed with a cold thruster body to obtain more data on the ignition issues identified during Plum Brook testing. These tests will explore improvements to the operating box through adjustments to engine mixture ratio, spark energy, and spark duration. Transient fluid and thermal models will be 
refined to address some of the results discussed here, and validated with test data. Specific emphasis will be placed on validating a water hammer model to predict the large amplitude transients observed during valve openings. Data gathered will also be utilized to anchor a system level thermal model.

\section{Acknowledgments}

ICPTA vehicle development was funded by the JSC Engineering Directorate, Laurie Hansen, Director, and RCS component-level tests were funded by JSC Propulsion and Power Division, Edgar Castro, Chief. Plum Brook HotFire facility testing was funded by the NASA Rocket Propulsion Test Management Board, Roger Simpson, Chair, and Glenn Research Center Plum Brook Propulsion Test Facility, Gerald Hill, Lead. Additional travel funding for hot-fire testing at Plum Brook was funded by NASA Advanced Exploration Systems, Jason Crusan, Head, and John Olansen at JSC.

Mark Lepore of WeaponX, LTD, provided vendor engineering design support for the coil technology development and design.

Patrick McManamen, Mark Villemarette, Pooja Desai, Jacob Collins, Brian Banker, John Applewhite, Christina Deoja, Bill Holten, Robert Fulmer, Marty Mclean, Mike Reddington, and Mike O'Donnel provided Propulsion and Power Engineering at JSC. University of El Paso students Daniela Aguilar, Mariano Mercado, Pedro Nunez, Armando Sandoval, Luz Bugarin and Mariana Chaidez provided buildup and test support at JSC and Plum Brook.

Hal Weaver, Brian Jones, John Zang, Nicolas Connelly, Chris Maloney, Wes Sallee, Brad Weisenberger, Jeremiah Folds, Sage Amato, and countless technicians and engineering staff conducted testing at Plum Brook. Ben Stiegemeier of NASA Glenn Research Center and Andrew Guymon of NASA Stennis Space Center provided additional test engineering support.

Integrated ICTPA vehicle testing at JSC was conducted with the efforts of James Rice, Ian Young, Jennifer Devolites, Steve Daniel, Jessie Zapata, Fred Shetz, Robert Hirsch, Ronnie Gambrel, Kent Dekome, Dave Swartwout, Randy Wade, and the hard work of the JSC riggers and technicians.

\section{References}

${ }^{1}$ Smith, T.D., Klem, M.K., and Fisher, K., "Propulsion Risk Reduction Activities for Non-Toxic Cryogenic Propulsion" AIAA-2010-8680, AIAA Space 2010 Conference and Exposition, Anaheim, CA, August 30 - September 2, 2010.

${ }^{2}$ Eric A. Hurlbert, Matthew J. Atwell, John C. Melcher, and Robert L. Morehead. "Integrated Pressure-Fed Liquid Oxygen / Methane Propulsion Systems - Morpheus Experience, MARE, and Future Applications", AIAA-2016-4681, 52nd AIAA/SAE/ASEE Joint Propulsion Conference, AIAA Propulsion and Energy Forum, Salt Lake City, UT, July 25-27, 2016.

${ }^{3}$ Hurlbert, E.A., Angstadt, T., Villamarette, M., Collins, J., Allred, J., Mahoney, J., and Peters, T., "870 lbf Reaction Control System Tests using LOX/Ethanol and LOX/methane at White Sands Test Facility", AIAA-2008-5247, 44 ${ }^{\text {th }}$ AIAA/ASME/SAE/ASEE Joint Propulsion Conference and Exhibit, Hartford, CT, July 21-23, 2008.

${ }^{4}$ Flynn, H., Lusby, B., Villemarette, M., "Liquid Oxygen / Liquid Methane Integrated Propulsion System Test Bed", AIAA2011-, 44 ${ }^{\text {th }}$ AIAA/ASME/SAE/ASEE Joint Propulsion Conference and Exhibit, Hartford, CT, July 21-23, 2008.

${ }^{5}$ McManamen, J.P., Hurlbert, E.A., and Kroeger, D.J., "Development and Flight Operation of a 5 lbf to 20 lbf O2/CH4 Roll Control Engine for Project Morpheus," AIAA-2014-3589, 50 ${ }^{\text {th }}$ AIAA/ASME/SAE/ASEE Joint Propulsion Conference, Cleveland, OH, July 28-30, 2014.

${ }^{6}$ Robert L. Morehead, Matthew J. Atwell, John C. Melcher, and Eric A. Hurlbert. "Cold Helium Pressurization for Liquid Oxygen / Liquid Methane Propulsion Systems: Fully-Integrated Initial Hot-Fire Test Results", AIAA-2016-4682, 52nd AIAA/SAE/ASEE Joint Propulsion Conference, AIAA Propulsion and Energy Forum, Salt Lake City, UT, July 25-27, 2016.

${ }^{7}$ Morehead, R.L., Melcher, J.C., Atwell, M.J., Hurlbert, E.A., Desai, P., and Werlink, R., "Vehicle-Level Oxygen/Methane Propulsion System Hotfire Testing at Thermal Vacuum Conditions," AIAA Propulsion and Energy Forum, Atlanta, GA, July 10 $12,2017$.

${ }^{8}$ Melcher, J.C., Atwell, M.J., Morehead, R.L., and Hurlbert, E.A., "Coil-On-Plug Ignition for LOX/Methane Liquid Rocket Engines in Thermal Vacuum Environments,” AIAA Propulsion and Energy Forum, Atlanta, GA, July 10 -12, 2017.

${ }^{9}$ Porca, P., Lema, M., Rambaud, P., Steelant, J., "Experimental and Numerical Multiphase-Front Fluid Hammer," Journal of Propulsion and Power, Vol. 30, No. 2, March-April 2014. 
${ }^{10}$ Wylie, B., Streeter, V., Fluid Transients, McGraw-Hill Inc., New York, 1978, pp. 17-23.

${ }^{11}$ Jimenez, R., Flores, S., Romig, K., and Hurlbert, E., "Characterization of a Thermodynamic Vent System (TVS) for an On Orbit Cryogenic Reaction Control Engine (RCE) Feed System," AIAA-2008-4553, 44 ${ }^{\text {th }}$ AIAA/ASME/SAE/ASEE Joint Propulsion Conference and Exhibit, Hartford, CT, July 21-23, 2008. 